\title{
ESCOLHA E DECISÃO EM SITUAÇÃO DE INCERTEZA E RISCO
}

Wilson Ferreira Menezes ${ }^{1}$

\section{Resumo}

As condições lógicas para as escolhas individuais normalmente são analisadas em um ambiente de raridade com informação perfeita, em que os agentes buscam maximizar suas funções de satisfação levando em conta suas restrições. No entanto, a incerteza e o risco encontram-se presentes em todos os aspectos cotidianos da vida, de maneira que o estudo desses aspectos devem permitir que as decisões sejam tomadas de maneira mais realística. O trabalho inicialmente analisa vários critérios para uma escolha e decisão com racionalidade; em seguida a teoria da utilidade esperada de von Neumann e Morgenstern é apresentada, bem como seus principais paradoxos. As teorias das perspectivas e das probabilidades não aditivas abrem novos campos de investigação nesse ambiente de incerteza e risco. Algumas considerações dessas teorias são incorporadas ao texto.

Palavras-Chaves: Incerteza. Risco. Decisão.

\section{Abstract}

The logical conditions for the individual choices are usually analyzed in a rare environment with perfect information, where agents search to

${ }^{1}$ É doutor em Programação para o desenvolvimento pela Universidade de Paris I, é professor associado do Curso de Mestrado em Economia da Universidade Federal Bahia, e-mail: awilson@ufba.br. 
maximize their satisfaction functions taking into account their limitations. However, the uncertainty and risk are present in all aspects of daily life, so that the study of these aspects allows decisions more realistically. The paper initially considers several criteria for a rational choice and decision, and then the expected utility theory of von Neumann and Morgenstern is presented as well as main paradoxes. Theories of the prospects and probabilities not additive open new fields of research in this environment of uncertainty and risk. Some considerations of these theories are incorporated into the text.

Key-Words: Uncertainty. Risk. Decision.

jel classification: d81.

\section{Introdução}

As decisões normalmente obedecem a escolhas, de maneira que dispor de um corpo teórico que explique a formação das escolhas contribuirá na determinação das decisões. Em uma primeira abordagem, a teoria econômica apresenta essa possibilidade em um quadro de referência em que o risco e a incerteza não têm lugar. Em um segundo momento, a hipótese de ausência de risco deve ser relaxada para se possam enfrentar situações mais complexas, em que as decisões são tomadas em ambiente de risco e incerteza. Nesse momento, é importante dispor de critérios para se processarem as escolhas e, com isso, melhorar os processos de decisão. Quando o ambiente é de risco e incerteza, deve-se mais do que nunca assegurar uma lógica de reflexão para que se possa manter um comportamento racional e, com isso, mais facilmente alcançar os objetivos desejados. Um comportamento racional requer regras, as quais devem ser obedecidas. Essas regras serão mais facilmente aplicadas quando o risco e a incerteza ganham significado quantitativo, podendo ser operado pelo cálculo da probabilidade objetiva, bem como através de variáveis aleatórias. ${ }^{2}$

A quantificação do risco permite operações algébricas e cálculos que facilitam a compreensão dos fenômenos e suas evoluções. Na presença de risco e incerteza, fenômenos podem então ser caracterizados e avaliados a partir de diferentes estados da natureza $\left(\mathrm{e}_{\mathrm{i}}\right)$, além de variáveis aleatórias $\left(\mathrm{X}_{\mathrm{i}}\right)$ que

\footnotetext{
${ }^{2}$ Uma variável aleatória é, em verdade, uma função que associa um número real a cada evento passível de prova. Por exemplo, o lançamento de uma moeda não viciada permite imaginar duas possibilidades de resultados: cara ou coroa. Pode-se então associar o número zero a cara e o número um a coroa e assim constituir uma variável aleatória. Esse é o procedimento usual na economia, para o tratamento de inúmeras variáveis, tais como gênero, raça, categoria profissional etc. (GUERRIEN; NEZEYS, 1987)
} 
associam um número real a cada possível estado da natureza. Dessa forma, é possível supor que se está sempre diante de um universo probabilístico, em que os agentes conhecem os acontecimentos possíveis associados a uma prova e que esses acontecimentos têm uma probabilidade de ocorrência, mesmo que essa probabilidade possa divergir entre os agentes. (GUERRIEN; NEZEYS, 1987)

Não existe um modelo único para a definição dos critérios que levam às preferências, de maneira a permitir, de maneira inequívoca, que os agentes econômicos realizem suas escolhas na presença de risco e incerteza na economia. Muito pelo contrário, diferentes métodos de avaliação acompanham a própria história do risco. Este trabalho busca uma avaliação dos critérios de escolha em ambientes de risco e incerteza, bem como realça as deficiências e virtudes nos processos de tomada de decisão. Para desenvolver essa avaliação, dividiu-se o texto em seis partes, além desta introdução. A segunda parte apresenta diferentes métodos de avaliação do risco em situações não mensuráveis e mensuráveis. A terceira parte apresenta a utilidade esperada de von Neumann e Morgenstern, seus axiomas e índices de aversão ao risco. A quarta parte levanta os problemas que rompem com a lógica interna da teoria da utilidade esperada, o que é feito através de uma apresentação dos paradoxos de Allais e Ellsberg. Em seguida, são apresentados e discutidos dois modelos alternativos à teoria da utilidade esperada: a teoria das perspectivas (quinta parte) e o modelo das probabilidades não aditivas (sexta parte). Finalmente, algumas conclusões são sugeridas.

\section{Racionalidade de Escolha e Decisão}

A teoria da decisão integra diferentes tipos de incerteza. Dessa forma, pode-se aplicá-la a problemas de decisão de agentes situados em ambientes muito diversificados. Nesse momento, as escolhas são analisadas à luz da teoria econômica e dos métodos econométricos. No caso de um seguro, a análise dos riscos leva em consideração o valor do objeto a ser assegurado, o custo de sua possível reposição e a importância dos acontecimentos que podem significar riscos. No caso de um portfólio, devem-se levar em consideração os rendimentos do ativo e a variabilidade desses rendimentos.

A teoria leva em conta as situações em que a incerteza decorre de variáveis com distribuição de probabilidade conhecida. As estimativas dessas probabilidades são feitas com base em informações passadas, as quais são eventualmente corrigidas por informações mais recentes. A explicação de situações dessa natureza é formalizada pela teoria da utilidade esperada. Essa teoria, no entanto, apresenta muitos limites que conduziram à busca de outras abordagens, muitas das quais ainda se encontram em 
pleno desenvolvimento de suas possibilidades explicativas. As teorias que analisam o risco podem se estender às situações em que o risco pode apresentar um caráter subjetivo ou mesmo com ausência de informação; no primeiro caso, a lei de Bayes é grande auxiliar na construção de uma solução; no segundo, pode-se dizer que se trata muito mais de uma incerteza cuja realização não pode ser observada. No que se segue, busca-se apresentar algumas teorias que antecedem a teoria da utilidade esperada e os limites dessas teorias.

\section{I Risco e Incerteza em Knight}

Knight, em seu livro Risco, Incerteza e Lucro de 1921, distingue claramente duas situações que escapam ao domínio da informação perfeita, completa e gratuita:

O futuro se apresenta de maneira arriscada ou aleatória, em que o risco é objetivo ou subjetivo. No primeiro caso, quem decide pode objetivamente calcular a probabilidade de realização de um evento; no segundo caso, com risco subjetivo, quem decide não dispõe de uma base informacional objetiva, mas pode estimar uma probabilidade subjetiva que lhe permita tomar uma decisão.

Caso a pessoa que deve tomar a decisão não disponha de elementos para estimar uma probabilidade, seja ela objetiva ou subjetiva, que possa ser associada ao processo de decisão. Nesse momento, quem decide se encontra em uma situação de incerteza, sem que se possa dispor de nenhuma condição de previsibilidade.

A primeira situação requer uma distinção entre as probabilidades objetiva e subjetiva.

A probabilidade objetiva considera os acontecimentos repetitivos, tal como o lançamento de uma moeda ou um dado, que podem de maneira razoável caracterizar o conceito matemático de evento aleatório, independente e com probabilidades idênticas. A existência de uma relação entre o acontecimento repetitivo e o conceito matemático permite estimar uma probabilidade de realização.

A probabilidade subjetiva, por outro lado, pode ser interpretada como sendo uma medida do grau de confiança que uma pessoa aporta sobre a veracidade de uma dada proposição. A partir de elementos pessoais é possível obter as probabilidades de acontecimentos que não se repetem ou se repetem com frequência muito pequena. Como as sensações de 
confiança são diferenciadas entre as pessoas, fica evidente que essas diferenças devem condicionar uma diversidade de possibilidades de ação entre as pessoas. Nesse momento, julgamentos, apreciações e intenções devem ser considerados como inerentes a cada pessoa de per si, de maneira que as ações e decisões podem perfeitamente se diferenciar entre as pessoas. Uma dificuldade encontrada pela probabilidade subjetiva aparece quando se necessita admitir valores numéricos que a representem.

Quanto à situação de incerteza, tem-se que ela é considerada como única, de maneira que não pode ser redutível a um grupo de casos similares. Assim sendo, a incerteza não dispõe de elementos para estimar uma probabilidade de ocorrência. Nessas circunstâncias, uma previsão deve considerar dois tipos bem distintos de julgamento (MOUREAU; RIVAUD-DANSET, 2004): de uma parte, pode-se decidir com o auxílio de uma estimativa baseada na experiência pessoal ou mesmo baseada em um comportamento eminentemente intuitivo; de outra, pode-se decidir considerando a confiança que a pessoa aporta em sua estimativa. ${ }^{3} \mathrm{Em}$ um quadro analítico mais empírico, uma modelação do risco e da incerteza requer algumas noções que auxiliem uma tomada de decisão: a natureza e seus estados, as ações ou estratégias e as consequências ou resultados. Essas noções podem ser apresentadas em uma matriz que sintetiza as informações necessárias a um processo de decisão, tal como aparece a seguir.

Quadro 1: Ações possíveis por estado da natureza

\begin{tabular}{|c|c|c|c|}
\hline \multirow{2}{*}{ Ações } & \multicolumn{3}{|c|}{ Estados da Natureza } \\
\cline { 2 - 4 } & e1 & e2 & e3 \\
\hline a1 & R11 & R12 & R13 \\
\hline a2 & R21 & R22 & R23 \\
\hline a3 & R31 & R32 & R33 \\
\hline
\end{tabular}

Fonte: Adaptado de Jokung-Nguéna (2001).

O problema consiste em determinar a melhor ação ou estratégia possível, levando-se em consideração os diferentes estados da natureza pelas suas respectivas probabilidades de ocorrência. O critério de escolha pode ser caracterizado por uma função cardinal de valoração (V). Pode-se então dizer que quando a ação $\mathrm{a}_{\mathrm{k}}$ é preferida à ação $\mathrm{a}_{1}\left(a_{k} \succ a_{l}\right)$ equivale dizer que $V\left(a_{k}\right)>V\left(a_{l}\right)$.

\footnotetext{
${ }^{3}$ Cabem ainda duas observações. Uma relativa à probabilidade objetiva que pode ser transformada em uma probabilidade subjetiva, por exemplo, é preciso acreditar que a moeda ou o dado não seja falso e, portanto, condicionem um determinado resultado. Outra relativa à dicotomia entre risco e incerteza, introduzida por Knight, a qual se encontra presente no senso comum das pessoas. Por exemplo, normalmente se fala de um risco de perda e de um ganho incerto.
} 


\subsection{Critérios de Decisão em Universo Não Mensurável}

As decisões em um universo não mensurável são consideradas como aquelas em que as probabilidades de ocorrência dos estados da natureza são desconhecidas, de maneira que a matriz de informação do problema é que fornecerá os elementos para uma decisão. Nessas condições, alguns critérios podem ser utilizados, dentre os quais se destacam os de Laplace, Maximax, Wald, Hurwicz, Savage e Média variabilidade.

Com o auxílio de um problema específico, esses diferentes critérios serão apresentados. Assim, para lançar um novo produto, uma firma pode escolher entre ações possíveis relativas à publicidade: Outdoor $\left(\mathrm{a}_{1}\right), \mathrm{Te}-$ levisão $\left(\mathrm{a}_{2}\right)$ ou Jornais $\left(\mathrm{a}_{3}\right)$. Os resultados da campanha publicitária serão diferentes em função dos diferentes estados da natureza quanto à concorrência a ser enfrentada: fraca $\left(e_{1}\right)$, média $\left(e_{2}\right)$ ou forte $\left(e_{2}\right)$. Sabe-se que a firma ignora as probabilidades associadas a cada nível de concorrência, mas pode perfeitamente estimar os resultados relativos a cada uma das ações. Os valores desses resultados se encontram na matriz a seguir.

Quadro 2: Ações possíveis por diferentes estados da natureza

\begin{tabular}{|c|c|c|c|}
\hline \multirow{2}{*}{ Ações } & \multicolumn{3}{|c|}{ Níveis da Concorrência } \\
\cline { 2 - 5 } & $\begin{array}{c}\text { Fraca } \\
\left(\mathbf{e}_{\mathbf{1}}\right)\end{array}$ & $\begin{array}{c}\text { Média } \\
\left(\mathbf{(}_{\mathbf{2}}\right)\end{array}$ & $\begin{array}{c}\text { Forte } \\
\left(\mathbf{e}_{\mathbf{3}}\right)\end{array}$ \\
\hline Outdoor $\quad\left(\mathbf{a}_{\mathbf{1}}\right)$ & 12 & -6 & 24 \\
\hline Televisão $\left(\mathbf{a}_{\mathbf{2}}\right)$ & 36 & 12 & 48 \\
\hline Jornais $\quad\left(\mathbf{a}_{3}\right)$ & -3 & 60 & 30 \\
\hline
\end{tabular}

Fonte: Jokung-Nguéna (2001).

Como as probabilidades de ocorrência dos níveis de concorrência são desconhecidas, significa dizer que se está diante de um ambiente de incerteza no sentido de Knight. O conhecimento da matriz de informações permite a determinação da melhor ação a ser tomada, levando-se em consideração diferentes critérios de decisão, os quais serão apresentados e analisados a seguir.

\subsection{Critério de Laplace}

O critério de Laplace busca integrar, em um único valor, as diferentes consequências possíveis de uma decisão em condições de incerteza. Trata-se de um critério muito simples, que condiciona esse único valor ao cálculo da média aritmética dos possíveis ganhos nos diferentes estados 
da natureza. O cálculo da média aritmética naturalmente impõe uma ponderação uniforme para os estados da natureza. Isso pode ser atribuído à ausência de informação em relação aos possíveis acontecimentos.

\begin{tabular}{|c|c|c|c|c|}
\hline \multirow{2}{*}{ Ações } & \multicolumn{3}{|c|}{ Níveis da Concorrência } & \multirow{2}{*}{ Média } \\
\cline { 2 - 5 } & $\begin{array}{c}\text { Fraca } \\
\left(\mathbf{(}_{\mathbf{1}}\right)\end{array}$ & $\begin{array}{c}\text { Média } \\
\left(\mathbf{e}_{\mathbf{2}}\right)\end{array}$ & $\begin{array}{c}\text { Forte } \\
\left(\mathbf{e}_{\mathbf{3}}\right)\end{array}$ & \\
\hline Outdoor $\quad\left(\mathbf{a}_{\mathbf{1}}\right)$ & 12 & -6 & 24 & 10 \\
\hline Televisão $\left(\mathbf{a}_{\mathbf{2}}\right)$ & 36 & 12 & 48 & $\mathbf{3 2}$ \\
\hline Jornais $\quad\left(\mathbf{a}_{\mathbf{3}}\right)$ & -3 & 60 & 30 & 29 \\
\hline
\end{tabular}

Fonte: Adaptado de Jokung-Nguéna (2001).

Segundo o critério de Laplace, em que cada estratégia é avaliada por sua respectiva média, podem-se classificar os resultados encontrados, em ordem crescente, para se alcançar a melhor solução. Dessa forma, pode-se dizer que a melhor estratégia é apostar na publicidade realizada pela televisão (ação $\mathrm{a}_{2}$ ), já que é essa estratégia que proporciona o resultado médio mais elevado.

\subsection{Critério de Maximax}

Trata-se de um critério ainda mais simples que o de Laplace. A solução ótima consiste em selecionar o mais elevado resultado, dentre os maiores valores da diferentes estratégias, segundo os diferentes estados da natureza. Daí o nome Maximax. Como a decisão busca maximizar dentre os máximos resultados, pode-se perfeitamente afirmar que o uso desse critério, próprio a uma pessoa decididamente otimista, que dificilmente pode ser considerado como um jogador.

Quadro 4: Ações possíveis por níveis da concorrência

\begin{tabular}{|c|c|c|c|c|}
\hline \multirow{2}{*}{ Ações } & \multicolumn{3}{|c|}{ Níveis da Concorrência } & \multirow{2}{*}{$\begin{array}{c}\text { Maiores } \\
\text { valores }\end{array}$} \\
\cline { 2 - 4 } & $\begin{array}{c}\text { Fraca } \\
\left(\mathbf{e}_{\mathbf{1}}\right)\end{array}$ & $\begin{array}{c}\text { Média } \\
\left(\mathbf{e}_{\mathbf{2}}\right)\end{array}$ & $\begin{array}{c}\text { Forte } \\
\left(\mathbf{e}_{\mathbf{3}}\right)\end{array}$ & 24 \\
\hline Outdoor $\quad\left(\mathbf{a}_{\mathbf{1}}\right)$ & 12 & -6 & 24 & 48 \\
\hline Televisão $\left(\mathbf{a}_{\mathbf{2}}\right)$ & 36 & 12 & 48 & $\mathbf{6 0}$ \\
\hline Jornais $\quad\left(\mathbf{a}_{\mathbf{3}}\right)$ & -3 & 60 & 30 & 24 \\
\hline
\end{tabular}

Fonte: Adaptado de Jokung-Nguéna (2001).

Segundo o critério de Maximax, ainda classificando os resultados por ordem crescente, pode-se dizer que a melhor estratégia é apostar 
na publicidade realizada por jornais (ação $a_{3}$ ), pois é essa estratégia que proporciona o resultado máximo.

\subsection{Critério de Wald}

Trata-se de um critério também muito simples. O argumento é praticamente o inverso do critério Maximax, já que apresenta como solução o mais elevado resultado dentre os menores valores alcançados pelas diferentes estratégias, segundo os diferentes estados da natureza. Por essa razão, esse critério pode ser chamado de Maximin, ou seja, maximizar dentre os valores de resposta.

Quadro 5 - Ações possíveis por níveis da concorrência

\begin{tabular}{|c|c|c|c|c|}
\hline \multirow{2}{*}{ Ações } & \multicolumn{3}{|c|}{ Níveis da Concorrência } & \multirow{2}{*}{$\begin{array}{c}\text { Menores } \\
\text { valores }\end{array}$} \\
\cline { 2 - 5 } & $\begin{array}{c}\text { Fraca } \\
\left(\mathbf{e}_{\mathbf{1}}\right)\end{array}$ & $\begin{array}{c}\text { Média } \\
\left(\mathbf{e}_{\mathbf{2}}\right)\end{array}$ & $\begin{array}{c}\text { Forte } \\
\left(\mathbf{e}_{\mathbf{3}}\right)\end{array}$ & -6 \\
\hline Outdoor $\quad\left(\mathbf{a}_{\mathbf{1}}\right)$ & 12 & -6 & 24 & $\mathbf{1 2}$ \\
\hline Televisão $\left(\mathbf{a}_{\mathbf{2}}\right)$ & 36 & 12 & 48 & -3 \\
\hline Jornais $\quad\left(\mathbf{a}_{\mathbf{3}}\right)$ & -3 & 60 & 30 & \\
\hline
\end{tabular}

Fonte: Adaptado de Jokung-Nguéna (2001).

Após classificar os resultados por ordem crescente, a melhor estratégia, segundo o critério de Wald, consiste em escolher a publicidade realizada pela televisão (ação $a_{2}$ ), já que esse é o maior resultado dentre os menores possíveis.

\subsection{Critério de Hurwicz}

hurwicz estabeleceu um critério de decisão bem similar aos critérios Maximax e Minimax. Mas ao invés de considerar os valores máximos ou mínimos, ele propôs uma ponderação assimétrica de dois dos valores retidos: o pior valor, ponderado pelo coeficiente $(\alpha)$ e o melhor valor, ponderado pelo coeficiente $(1-\alpha)$. O chamado coeficiente de Hurwicz resulta, portanto, da maximização da soma das ponderações estabelecidas. Esse coeficiente $\alpha$ expressa o grau de pessimismo de quem deve decidir e varia dentro do intervalo $[0,1]$. Não é difícil perceber que quando $\alpha=0$, retorna-se ao critério de Maximax, e quando $\alpha=1$, tem-se de volta o critério de Maximin de Wald. 
Quadro 6: Ações possíveis por níveis ponderados da concorrência

\begin{tabular}{|c|c|c|c|c|c|c|}
\hline \multirow{2}{*}{ Ações } & \multicolumn{3}{|c|}{ Níveis da Concorrência } & \multicolumn{3}{c|}{ Com $\alpha=1 / 3$} \\
\cline { 2 - 7 } & $\begin{array}{c}\text { Fraca } \\
\left(\mathrm{e}_{1}\right)\end{array}$ & $\begin{array}{c}\text { Média } \\
\left(\mathrm{e}_{2}\right)\end{array}$ & $\begin{array}{c}\text { Forte } \\
\left(\mathrm{e}_{3}\right)\end{array}$ & Pior & Melhor & Soma \\
\hline Outdoor $\left(\mathrm{a}_{1}\right)$ & 12 & -6 & 24 & -2 & 16 & 14 \\
\hline Televisão $\left(\mathrm{a}_{2}\right)$ & 36 & 12 & 48 & 4 & 32 & 36 \\
\hline Jornais $\left(\mathrm{a}_{3}\right)$ & -3 & 60 & 30 & 20 & 20 & 40 \\
\hline
\end{tabular}

Fonte: Adaptado de Jokung-Nguéna (2001).

A título de exemplo, vai-se considerar $\alpha=1 / 3$, de maneira que $(1-\alpha)=2 / 3$. Após as devidas ponderações e a classificação dos resultados por ordem crescente, pode-se selecionar a melhor estratégia. Segundo esse critério, a escolha deve recair na publicidade realizada por jornais (ação $a_{3}$ ), pois esse é o resultado que proporciona o mais elevado coeficiente de Hurwicz.

\subsection{Critério de Savage}

Savage incorporou em seu processo de decisão uma função denominada de arrependimento. Trata-se de uma função que mede o ressentimento de uma decisão equivocada quando da escolha da ação. Dessa forma, considerando cada estado da natureza, estima-se a função de arrependimento pela diferença entre os resultados das ações disponíveis e o melhor resultado possível e realizado. A melhor ação de cada estado da natureza serve, portanto, de base para mensurar as funções de arrependimento. Essa função é expressa pela agregação dessas diferenças, segundo as diferentes estratégias possíveis. A estratégia ótima será então aquela que proporciona o menor grau de arrependimento.

Quadro 7: Ações possíveis por níveis da concorrência e funções de arrependimento

\begin{tabular}{|c|c|c|c|c|c|c|c|}
\hline \multirow{3}{*}{ Ações } & \multicolumn{3}{|c|}{ Níveis da Concorrência } & \multicolumn{4}{|c|}{ Funções de Arrependimento } \\
\hline & \multirow{2}{*}{$\begin{array}{c}\text { Fraca } \\
\left(\mathrm{e}_{1}\right)\end{array}$} & \multirow{2}{*}{$\begin{array}{c}\text { Média } \\
\left(\mathrm{e}_{2}\right)\end{array}$} & \multirow{2}{*}{$\begin{array}{c}\text { Forte } \\
\left(\mathrm{e}_{3}\right)\end{array}$} & Para $e_{1}$ & Para $e_{2}$ & Para $e_{3}$ & \multirow{2}{*}{ Soma } \\
\hline & & & & $\begin{array}{l}\mathrm{R}_{\text {melhor }} \\
-\mathrm{Ra} 1\end{array}$ & $\begin{array}{l}\mathrm{R}_{\text {melhor }} \\
\text {-Ra2 }\end{array}$ & $\begin{array}{l}R_{\text {melhor }} \\
\text {-Ra33 }\end{array}$ & \\
\hline Outdoor $\left(\mathrm{a}_{1}\right)$ & 12 & -6 & 24 & 24 & 66 & 24 & 114 \\
\hline Televisão $\left(\mathrm{a}_{2}\right)$ & 36 & 12 & 48 & 0 & 48 & 0 & 48 \\
\hline Jornais $\quad\left(a_{3}\right)$ & -3 & 60 & 30 & 39 & 0 & 18 & 57 \\
\hline
\end{tabular}

Fonte: Adaptado de Jokung-Nguéna (2001). 
Após a realização das diferenças entre o resultado de cada ação e o resultado da melhor ação possível, em cada estado da natureza, procede-se à agregação dessas diferenças para se chegar às estimativas das funções de arrependimento. Pelo critério de Savage, a escolha ótima deve recair na publicidade realizada pela televisão (ação $\mathrm{a}_{2}$ ), pois esse é o resultado que proporciona o menor grau de arrependimento.

\subsection{Critério da Média Variabilidade}

Quando as estratégias são avaliadas apenas por suas médias, as respectivas variabilidades ficam descartadas, impossibilitando a observação da aleatoriedade das estratégias. Para que isso não aconteça, cada estratégia deve ser caracterizada pela variabilidade dos resultados, além da média. Essa variabilidade é medida pela diferença entre o melhor e o pior resultado. Pode-se então presumir que o melhor resultado é aquele que apresente a média mais elevada combinada com a menor variabilidade. A relação entre a média e a variabilidade de cada estratégia é uma boa medida para se alcançar o resultado ótimo. A solução é encontrada, ao se comparar essas relações aos pares, devendo recair a escolha na mais elevada relação.

Considerando que uma relação de preferência entre duas estratégias é dada por $a_{k} \succ a_{l}$, existem dois casos para se comparar e escolher as estratégias a partir das relações entre a média e a variabilidade. Pode-se considerar que $a_{k} \succ a_{l}$ em duas situações:

Primeira situação: Comparando as estratégias através da proporção da média dos resultados nos diferentes estados da natureza por suas respectivas variabilidades. Assim, se média $\left(a_{k}\right) / \ddot{A}\left(a_{k}\right)>$ média $\left(a_{l}\right) / \ddot{A}\left(a_{l}\right)$ então a melhor solução é ak.

Segunda situação: Introduzindo uma noção de deslocamento; nesse caso, o deslocamento da estratégia ak para a estratégia al será realizado se a taxa de substituição $(\lambda)$ entre as estratégias for elevada, sem que isso altere o grau de satisfação de quem decide. Dessa forma, se $\left\{\left[\right.\right.$ média $\left(a_{k}\right)-$ média $\left.\left.\left(a_{1}\right)\right] /\left[\Delta\left(a_{k}\right)-\Delta\left(a_{1}\right)\right]\right\}>\lambda$ então a melhor solução é $\mathrm{a}_{\mathrm{k}}$. 
Quadro 8: Ações possíveis por níveis da concorrência e deslocamentos

\begin{tabular}{|c|c|c|c|c|c|c|}
\hline \multirow[b]{2}{*}{ Ações } & \multicolumn{3}{|c|}{ Níveis da Concorrência } & \multicolumn{3}{|c|}{ Primeiro Caso } \\
\hline & $\begin{array}{c}\text { Fraca } \\
\left(\mathrm{e}_{1}\right)\end{array}$ & $\begin{array}{c}\text { Média } \\
\left(\mathrm{e}_{2}\right)\end{array}$ & $\begin{array}{l}\text { Forte } \\
\left(\mathrm{e}_{3}\right)\end{array}$ & Média & $\begin{array}{l}\text { Variabi- } \\
\text { lidade }\end{array}$ & $\begin{array}{c}\text { Média / } \\
\text { Variabilidade }\end{array}$ \\
\hline Outdoor $\left(a_{1}\right)$ & 12 & -6 & 24 & 10 & 30 & 0,33 \\
\hline Televisão $\left(\mathrm{a}_{2}\right)$ & 36 & 12 & 48 & 32 & 36 & 0,89 \\
\hline Jornais $\quad\left(a_{3}\right)$ & -3 & 60 & 30 & 29 & 63 & 0,46 \\
\hline
\end{tabular}

Fonte: Adaptado de Jokung-Nguéna (2001).

Após a realização dos devidos cálculos, conclui-se que a escolha ótima, nesse primeiro caso, deve recair na publicidade realizada pela televisão (ação $\mathrm{a}_{2}$ ), pois esse é o resultado que proporciona a maior relação entre a média e a variabilidade.

Quadro 9: Ações possíveis por níveis da concorrência e deslocamentos

\begin{tabular}{|c|c|c|c|c|c|c|c|c|c|}
\hline \multirow[b]{2}{*}{ Ações } & \multicolumn{3}{|c|}{ Níveis da Concorrência } & \multicolumn{6}{|c|}{ Segundo Caso } \\
\hline & $\begin{array}{c}\text { Fraca } \\
\left(\mathrm{e}_{1}\right)\end{array}$ & $\begin{array}{c}\text { Média } \\
\left(\mathrm{e}_{2}\right)\end{array}$ & $\begin{array}{c}\text { Forte } \\
\left(\mathrm{e}_{3}\right)\end{array}$ & Média & $\begin{array}{c}\Delta= \\
\text { Rmaior- } \\
\text { Rmenor }\end{array}$ & $\begin{array}{l}\text { Estima- } \\
\text { tiva }\end{array}$ & $\begin{array}{l}\text { Média } \\
\mu \mathrm{i}-\mu \mathrm{j}\end{array}$ & $\begin{array}{c}\text { Variab. } \\
\Delta \mathrm{i}-\Delta \mathrm{j}\end{array}$ & $\mathrm{Mi} / \Delta \mathrm{j}$ \\
\hline Outdoor $\left(a_{1}\right)$ & 12 & -6 & 24 & 10 & 30 & \multirow{2}{*}{$\mu 2-\mu 1$} & \multirow{2}{*}{22} & \multirow{2}{*}{6} & \multirow{2}{*}{3,7} \\
\hline Televisão $\left(\mathrm{a}_{2}\right)$ & 36 & 12 & 48 & 32 & 36 & & & & \\
\hline Jornais $\quad\left(a_{3}\right)$ & -3 & 60 & 30 & 29 & 63 & $\mu 2-\mu 3$ & 3 & -27 & $-0,1$ \\
\hline
\end{tabular}

Fonte: Adaptado de Jokung-Nguéna (2001).

Os resultados devem então ser comparados ao valor de $\lambda$, de maneira que para alguns valores de $\lambda$, $a_{2}$ é a melhor solução, e para outros, $a_{1}$ é a melhor solução. A decisão ótima consiste em escolher dentre as seguintes estratégias:

$$
a^{*}= \begin{cases}a_{1} & \text { se } \lambda>3,7 \\ a_{1} & \text { ou } a_{2} \text { se } \lambda=3,7 \\ a_{2} & \text { se } \lambda<3,7\end{cases}
$$

A experiência ou uma moeda pode auxiliar na decisão. 
Quadro 10: Síntese dos resultados em universo não mensurável

\begin{tabular}{|c|c|c|c|c|c|c|c|}
\hline \multirow{2}{*}{ Ações } & \multirow{2}{*}{$\begin{array}{l}\text { Laplace } \\
\text { Média }\end{array}$} & \multirow{2}{*}{$\begin{array}{l}\text { Maximax } \\
\text { Maior } \\
\text { valor }\end{array}$} & \multirow{2}{*}{$\begin{array}{l}\text { Wald } \\
\text { Menor } \\
\text { valor }\end{array}$} & \multirow{2}{*}{$\begin{array}{c}\text { Hurwicz } \\
\text { Pondera } \\
\text { maior e } \\
\text { menor } \\
\text { valor }\end{array}$} & \multirow{2}{*}{$\begin{array}{c}\text { Savage } \\
\text { Menor } \\
\text { arrependimento }\end{array}$} & \multicolumn{2}{|c|}{$\begin{array}{c}\text { Média/ } \\
\text { Variabilidade }\end{array}$} \\
\hline & & & & & & 1o caso & $\begin{array}{l}20 \\
\text { caso }\end{array}$ \\
\hline Outdoor $\left(a_{1}\right)$ & 10 & 24 & -6 & 14 & 114 & 0,33 & \\
\hline $\begin{array}{c}\text { Televisão } \\
\left(\mathrm{a}_{2}\right)\end{array}$ & 32 & 48 & 12 & 36 & 48 & 0,89 & 3,7 \\
\hline Jornais $\quad\left(a_{3}\right)$ & 29 & 60 & -3 & 40 & 57 & 0,46 & \\
\hline
\end{tabular}

\section{Critérios de Decisão em Universo Mensurável}

As decisões em um universo mensurável são consideradas como aquelas em que, além da matriz de informação do problema, se dispõe do conhecimento das probabilidades de ocorrência dos estados da natureza, tornando o ambiente de decisão mais rico em informações para uma decisão. Diferentes critérios serão apresentados com o auxílio da mesma matriz de informação do problema anterior, à qual serão acrescidas as probabilidades de ocorrência dos diferentes estados da natureza.

Assim, os resultados da campanha publicitária serão diferenciados em função das probabilidades de ocorrência dos diferentes estados da natureza quanto à concorrência a ser enfrentada: fraca $\left(\mathrm{e}_{1}\right)$ com probabilidade de $25 \%$, média $\left(\mathrm{e}_{2}\right)$ com probabilidade de $50 \%$ ou forte $\left(\mathrm{e}_{2}\right)$ com probabilidade de $25 \%$. Como a firma não mais ignora as probabilidades associadas a cada nível de concorrência, estamos diante de uma situação de risco, em que essas probabilidades podem influenciar e modificar a escolha.

Nessas condições, alguns outros critérios são considerados, dentre os quais se destacam os de Pascal, Markowitz, Bernoulli e o do Valor Esperado com Informação Perfeita (Veip).

\section{I Critério de Pascal}

Para um entendimento do critério de Pascal, necessário se faz a definição de esperança matemática. Considerando uma variável aleatória (X) que assume diversos valores, tais como $X_{1}, X_{2}, \ldots, X_{n}$, com probabilidades de ocorrência dadas por $P\left(X_{1}\right) P\left(X_{2}\right) \ldots, P\left(X_{n}\right)$, a esperança matemática pode ser estimada por: 


$$
\begin{aligned}
& E(X)=\sum_{i=1}^{n} X_{i} P\left(X_{i}\right) \text {, se a variável aleatória é discreta. } \\
& E(X)=\int X f(X) d X, \text { se a variável aleatória é contínua. }
\end{aligned}
$$

O critério de Pascal estima que a escolha ótima deva recair na estratégia que detém a mais elevada esperança matemática. Dessa forma, as ações podem ser classificadas segundo as esperanças matemáticas de suas

\begin{tabular}{|c|c|c|c|c|c|c|c|}
\hline \multirow{3}{*}{ Ação } & \multicolumn{3}{|c|}{ Informações } & \multicolumn{3}{|c|}{ Cálculos } & \multirow{3}{*}{$\begin{array}{c}\text { Esperança } \\
\text { matemática }\end{array}$} \\
\hline & $\begin{array}{c}\text { Fraca } \\
\left(\mathrm{e}_{1}\right)\end{array}$ & $\begin{array}{c}\text { Média } \\
\left(\mathrm{e}^{2}\right)\end{array}$ & $\begin{array}{c}\text { Forte } \\
\left(\mathrm{e}_{3}\right)\end{array}$ & Fraca & Média & Forte & \\
\hline & $p=0,25$ & $p=0,5$ & $p=0,25$ & $p=0,25$ & $p=0,5$ & $p=0,25$ & \\
\hline Outdoor $\left(\mathrm{a}_{1}\right)$ & 12 & -6 & 24 & 3 & -3 & 6 & 6 \\
\hline Televisão $\left(\mathrm{a}_{2}\right)$ & 36 & 12 & 48 & 9 & 6 & 12 & 27 \\
\hline Jornais $\quad\left(a_{3}\right)$ & -3 & 60 & 30 & $-0,75$ & 30 & 7,5 & 36,75 \\
\hline
\end{tabular}
ocorrências, de maneira que $a_{k} \succ a_{1}$ se $E\left(a_{k}\right)>E\left(a_{1}\right)$.

Uma vez realizados os devidos cálculos, pode-se concluir que, pelo critério de Pascal, a escolha ótima corresponde à publicidade realizada através de jornais (ação $a_{3}$ ), pois esse é o resultado que proporciona a mais elevada esperança matemática.

\subsection{Critério de Markowitz}

O critério de Pascal constitui um avanço sobre os critérios de ambientes não mensuráveis, isso porque a consideração das probabilidades de ocorrência dos estados da natureza acrescenta um grau de veracidade aos resultados. No entanto, falta uma dimensão de variabilidade nesse critério. Essa dimensão já foi incorporada no critério da Média variabilidade, no entanto seu caráter muitas vezes ambíguo ${ }^{4}$ faz com que a noção de variância seja mais pertinente para estimativas do risco. A variância $\left(o_{x}^{2}\right)$ de uma variável aleatória $(X)$ é dada pela divisão da soma do quadrado dos desvios pelo número de observações. Em um ambiente em que a variável aleatória assume valores com probabilidades de ocorrência dadas por

\footnotetext{
${ }^{4} \mathrm{O}$ caráter amtbíguo da variabilidade aparece quando duas ações com as mesmas variabilidades, mas com probabilidades distintas, acabam por imprimir diferentes graus de risco. Por exemplo: $10(0,5)+10(0,25)-10(0,25)=5$, mas $10(0,5)-10(0,25)-10(0,25)=0$.
} 
$P\left(X_{1}\right) P\left(X_{2}\right) \ldots, P\left(X_{n}\right)$, estima-se a variância ${ }^{5}$ como:

1. $\sigma_{x}^{2}=\sum_{i=1}^{n} p_{i}\left(x_{i}-E\left(\bar{X}_{X}\right)\right)^{2}$, se a variável aleatória é discreta.

2. $\sigma_{x}^{2}=\int_{-\infty}^{+\infty}(x-E(X))^{2} f(x) d x$, se a variável aleatória é contínua.

Para Markowitz, cada estratégia é caracterizada pela esperança matemática, representando o rendimento, e pelo desvio padrão, ${ }^{6}$ representando o risco. ${ }^{7}$ (KAST, 1993) Dessa forma, uma pessoa avessa ao risco desejará maximizar a esperança de ganho e minimizar o risco. Ademais, utilizando-se desses dois indicadores, pode-se realizar uma comparação entre duas diferentes estratégias, o que é feito segundo uma das seguintes condições:

1. $a_{k} \succ a_{1}$ se $E\left(a_{k}\right) / \sigma\left(a_{k}\right)>E\left(a_{l}\right) / \sigma\left(a_{1}\right)$

2. $a_{k} \succ a_{1}$ se $\left\{\left[E\left(a_{k}\right)-E\left(a_{1}\right)\right] /\left[\sigma\left(a_{k}\right)-\sigma\left(a_{1}\right)\right]\right\}>\lambda$

A preferência por uma ação é então definida a partir de uma arbitragem entre a esperança matemática e o desvio padrão, de maneira que o valor de $\lambda$ expressa o grau de aversão pelo risco. Quando $\ddot{e}=0$, pode-se afirmar que a pessoa é indiferente quanto ao risco e quando $\ddot{e}=+\infty$, significa dizer que a pessoa não suporta nenhum tipo ou grau de risco. Uma avaliação empírica do critério de Markowitz considera duas situações, uma em que o grau de risco $(\lambda)$ é desconhecido e outra em que é conhecido. (JOKUNG-NGUÉNA, 2001) A seguir apresentam-se os resultados para as duas situações.

\footnotetext{
${ }^{5}$ Extraindo a raiz quadrada da variância chega-se ao conceito de desvio padrão, que em muitos casos se mostra mais pertinente, na medida em que expressa o resultado na mesma unidade de medida das ações.

${ }^{6}$ É possível que as pessoas observem mais a esperança matemática que o desvio padrão.

${ }^{7} \mathrm{O}$ uso desses dois indicadores é pioneiro na estimação do rendimento de um portfólio.
} 
Quadro 12 - Ações possíveis por níveis da concorrência e da variância $1^{\circ}$ caso - em que $\lambda$ é desconhecido

\begin{tabular}{|c|c|c|c|c|c|c|c|c|c|c|}
\hline \multirow{3}{*}{ Ação } & \multicolumn{3}{|c|}{ Concorrência } & \multirow{3}{*}{ Esp } & \multicolumn{4}{|c|}{ Variância } & \multirow{3}{*}{ DP } & \multirow{3}{*}{$\begin{array}{l}\text { Esp / } \\
\text { DP }\end{array}$} \\
\hline & $\begin{array}{c}\text { Fraca } \\
\left(\mathrm{e}_{1}\right)\end{array}$ & $\begin{array}{l}\text { Média } \\
\left(\mathrm{e}_{2}\right)\end{array}$ & $\begin{array}{l}\text { Forte } \\
\left(\mathrm{e}_{3}\right)\end{array}$ & & $\begin{array}{c}\text { Fraca } \\
\left(\mathrm{e}_{1}\right)\end{array}$ & $\begin{array}{l}\text { Média } \\
\left(\mathrm{e}_{2}\right)\end{array}$ & $\begin{array}{l}\text { Forte } \\
\left(\mathrm{e}_{3}\right)\end{array}$ & \multirow[t]{2}{*}{ Total } & & \\
\hline & $p=0,25$ & $p=0,5$ & $p=0,25$ & & $p=0,25$ & $p=0,5$ & $p=0,25$ & & & \\
\hline Outdoor $\left(\mathrm{a}_{1}\right)$ & 3 & -3 & 6 & 6 & 9 & 72 & 81 & 162,0 & 12,73 & 0,47 \\
\hline $\begin{array}{c}\text { Televisão } \\
\left(\mathrm{a}_{2}\right)\end{array}$ & 9 & 6 & 12 & 27 & 20,25 & 112,5 & 110,25 & 243,0 & 15,59 & 1,73 \\
\hline Jornais $\left(\mathrm{a}_{3}\right)$ & $-0,75$ & 30 & 7,5 & 36,75 & 395,0156 & 270,281 & 11,3906 & 676,7 & 26,01 & 1,41 \\
\hline
\end{tabular}

Realizados os devidos cálculos, pode-se concluir que, pelo critério de Markowitz a escolha ótima corresponde à publicidade realizada através da televisão (ação a2), pois esse é o resultado que proporciona a mais elevada relação entre a esperança matemática e o desvio padrão. Por esse critério, a ordem de preferência entre as estratégias é $a_{2} \succ a_{3} \succ a_{1}$.

Quadro 13 - Ações possíveis por níveis da concorrência e da variância $2^{\circ}$ caso - em que $\lambda$ é conhecido

\begin{tabular}{|c|c|c|c|c|c|}
\hline $\begin{array}{c}\lambda \text { é conhecido } \\
\text { Compara }\end{array}$ & $\Delta \mathrm{Esp}$ & $\Delta \mathrm{DP}$ & $\begin{array}{c}\Delta \mathrm{Esp} / \\
\mathrm{DDP}\end{array}$ & $\lambda$ & Escolha da ação \\
\hline $\mathrm{a}_{2}$ com $\mathrm{a}_{1}$ & 21 & 2,86 & 7,34 & $\lambda>7,34$ & $a_{3}$ se $\lambda \leq 0,93$ \\
\hline $\mathrm{a}_{2}$ com $\mathrm{a}_{3}$ & $-9,75$ & $-10,42$ & 0,94 & $\lambda<0,93$ & $a_{2}$ se $0,93 \leq \lambda \leq 7,34$ \\
\hline $\mathrm{A}_{3}$ com $\mathrm{a}_{1}$ & 30,75 & 13,29 & 2,31 & $\lambda<2,31$ & $a_{1}$ se $\lambda \geq 7,34$ \\
\hline
\end{tabular}

Fonte: Adaptado de Jokung-Nguéna (2001).

Pode ocorrer de $\lambda=0,93$, isso coloca as ações $\mathrm{a}_{3}$ e $\mathrm{a}_{2}$ como equivalentes; pode também ocorrer de $\lambda=7,34$, o que tornam as ações $a_{1}$ e $a_{2}$ como equivalentes. Nesses casos, a experiência, uma moeda lançada ao acaso ou alguma forma de desempate pode ser utilizada para uma tomada de decisão.

\subsection{Critério de Bernoulli}

Bernoulli identificou, em 1713, a presença de um paradoxo na análise da esperança matemática. Buscando superar esse paradoxo, introduziu a noção de utilidade esperada. Essa noção apareceu, portanto, como resposta ao paradoxo encontrado, permitindo um avanço na avaliação e análise do risco. 
Mundialmente conhecido, o chamado Paradoxo de São Petersburgo coloca em evidência a contradição entre uma primeira intuição lógica e o comportamento de um jogador. Assim, nenhum jogador arriscará toda sua fortuna em um jogo, mesmo que esse jogo aporte um ganho esperado infinitamente grande. Uma ilustração desse paradoxo pode ser feita através de um exemplo, ao mesmo tempo, simples e revelador. Uma moeda não viciada é lançada até que o lado cara apareça. Se cara aparece na enésima vez, o jogador terá direito ao ganho de $2^{\text {n }}$ unidades monetárias, deduzida a soma apostada pelo jogador. A questão é saber quantas unidades monetárias esse jogador deve apostar nesse jogo.

O cálculo da esperança de ganho $(\mathrm{E}(\mathrm{G}))$ permite apontar um resultado para esse jogo, tal como segue:

$$
E(G)=1 / 2(2)+1 / 2^{2}\left(2^{2}\right)+\ldots+1 / 2^{n}\left(2^{n}\right)+\ldots=1+1+\ldots+1 \ldots=\infty
$$

Como o número de lances desse jogo não é limitado, a esperança de ganho é infinita, de maneira que, para ser um jogo justo, o jogador deve apostar uma soma infinita de unidades monetárias. $\mathrm{O}$ paradoxo aparece quando se verifica que a maior parte dos jogadores não aceita participar desse jogo, ainda que a esperança de ganho seja infinita.

Diante desse paradoxo, Bernoulli propôs substituir a esperança matemática de ganho pela utilidade esperada desse ganho. O argumento para essa substituição advém da proposição de que todo aumento de riqueza proporciona um aumento da utilidade, mas a utilidade é inversamente proporcional à quantidade de bens. Essa proposição permitiu uma solução satisfatória ao Paradoxo de São Petersburgo, ao reduzir uma possível entrada no jogo proposto a uma soma relativamente baixa, mesmo que não tenha efetivado nenhuma evidência quanto à mensuração da utilidade.

Dessa forma, o paradoxo pode ser resolvido com o conceito de utilidade esperada substituindo a esperança de ganho e ao mesmo tempo limitando o valor da aposta, por exemplo, em 100 unidades monetárias. Dessa forma, a função anterior toma a seguinte forma:

$$
E(U(G))=1 / 2 \mathrm{U}(2)+1 / 2^{2} U\left(2^{2}\right)+\ldots+1 / 2^{n} U\left(2^{n}\right)+\ldots=\sum_{n=1}^{\infty} 1 / 2^{n} U\left(2^{n}\right)=100
$$

O valor limite de aposta não corresponde mais à esperança de ganho, mas à esperança de uma função desse ganho. Duas justificativas condicionam o comportamento da função de utilidade do ganho esperado (JOKUNG-NGUÉNA, 2001): 
1. O importante para as pessoas não é o ganho em si mesmo, mas a utilidade que esse ganho proporciona;

2. A satisfação das pessoas cresce cada vez menos rapidamente à medida que a riqueza aumenta.

A primeira justificativa explica a existência da função de utilidade do ganho esperado e a segunda reconhece o comportamento dessa função, ou seja, caracteriza o princípio da utilidade marginal decrescente e estabelece que esse princípio seja traçado por uma curva côncava quanto à origem, cuja derivada segunda é negativa. Essa função representa a aversão ao risco, já que ela cresce a taxas decrescentes. A função $U$ é chamada de utilidade do ganho esperado e o valor 100, no exemplo acima, é chamado de prêmio de risco, ou seja, aquilo que o jogador deseja pagar para participar do jogo. O prêmio é uma função linear das probabilidades dos ganhos, cuja propriedade é assegurar a independência das preferências em relação às loterias. A explicação sobre o comportamento dessa função faz com que o paradoxo desapareça.

Não obstante, ao aplicar o logaritmo neperiano à função de utilidade de Bernoulli, pode-se chegar à seguinte expressão:

$$
E(U(G))=1 / 2 \ln (2)+1 / 2^{2} \ln \left(2^{2}\right)+\ldots+1 / 2^{n} \ln \left(2^{n}\right)+\ldots=\sum_{n=1}^{\infty} 1 / 2^{n} \ln \left(2^{n}\right)=\ln (100)=u(4,6)
$$

Esse resultado é muito interessante, pois permite afirmar que esse jogo proporciona uma utilidade equivalente à $u(4,6)$, de maneira que uma pessoa, cuja função de utilidade tenha essas características, não disponibilizará mais do que $\$ 4,6$ para participar desse jogo. (JOKUNG-NGUÉNA, 2001) Dessa forma, o caráter paradoxal desaparece, quando se considera a utilidade como um fenômeno não linear. (MOUREAU; RIVAUD-DANSET, 2004)

Dessa forma, as pessoas jogam, mesmo quando a esperança de ganho é infinitamente pequena, isso porque elas não são guiadas pela esperança matemática do rendimento, mas pela esperança da utilidade desse rendimento. Assim, ao se admitir que a utilidade marginal do rendimento diminua à medida que o rendimento aumenta, resulta que a desutilidade da perda é sempre maior que a utilidade do ganho.

Em havendo muitas estratégias disponíveis, cada ação deve ser avaliada por sua esperança de utilidade, dada pela expressão: 


$$
E u\left(a_{i}\right) \cdot=\sum_{j=1}^{n} p_{j} u\left(R_{i, j}\right)
$$

de maneira que se pode perfeitamente classificar as ações por ordem crescente de utilidade. Dessa forma, $\mathrm{a}_{\mathrm{k}} \succ \mathrm{a}_{1}$ se $\operatorname{Eu}\left(\mathrm{a}_{\mathrm{k}}\right)>\operatorname{Eu}\left(\mathrm{a}_{1}\right) \cdot{ }^{8}$

Voltando ao exemplo original e considerando que a firma que irá lançar um novo produto detém uma função de utilidade com o formato de $u(W)=\ln (w+10)$. A partir de suas possíveis ações, pode-se então obter os resultados expressos no quadro a seguir.

\begin{tabular}{|c|c|c|c|c|}
\hline \multirow[b]{2}{*}{ Ação } & \multicolumn{3}{|c|}{ Considerando $u(w)=\ln (w+10)$} & \multirow{2}{*}{$\begin{array}{c}\text { Esperança da } \\
\text { utilidade }\end{array}$} \\
\hline & $\begin{array}{c}\text { Fraca } \\
\left(\mathrm{e}_{1}\right)\end{array}$ & $\begin{array}{c}\text { Média } \\
\left(\mathrm{e}_{2}\right)\end{array}$ & $\begin{array}{c}\text { Forte } \\
\left(\mathrm{e}_{3}\right)\end{array}$ & \\
\hline Outdoor $\left(a_{1}\right)$ & 0,77276 & 0,69315 & 0,88159 & 2,3475 \\
\hline Televisão $\left(\mathrm{a}_{2}\right)$ & 0,95716 & 1,54552 & 1,01511 & 3,5178 \\
\hline Jornais $\quad\left(a_{3}\right)$ & 0,48648 & 2,12425 & 0,92222 & 3,5329 \\
\hline
\end{tabular}

Nesses termos, conclui-se pelo critério de Bernoulli que a escolha ótima corresponde à publicidade realizada através de jornais (ação $\mathrm{a}_{3}$ ), pois esse é o resultado que proporciona a mais elevada esperança matemática da utilidade da riqueza. Ainda por esse critério, a preferência das estratégias segue a ordem: $a_{3} \succ a_{2} \succ a_{1}$.

\subsection{Cálculo do Valor Esperado com Informação Perfeita}

É possível aplicar o critério de Savage ao resultado obtido pelo critério de Pascal. Para tanto, determina-se para cada estado possível da natureza a ação que proporciona o menor arrependimento, ou seja, aquela que apresenta o valor mais elevado de retorno. Considerando esse valor como sendo $\mathrm{a}_{\text {ind(j) }}$ para o estado da natureza $\mathrm{e}_{\mathrm{i}^{\prime}}$ pode-se estimar o Valor Esperado com Informação Perfeita (Veip) a partir dos resultados obtidos pelo critério de Pascal.

O critério de Pascal definiu $a_{3}$ como a melhor estratégia, segundo os diferentes estados na natureza os valores dos rendimentos dessa estratégia

\footnotetext{
${ }^{8}$ É interessante lembrar que a fundamentação axiomática do modelo da utilidade esperada foi realizada por von Neumann e Morgenstern em Theory of games and economic behavior, 1947. (MOUREAU; RIVAUD-DANSET, 2004)
} 
foram (-3, 60 e 30), que podem ser caracterizados como provenientes de uma decisão a priori. Ainda por esse critério, os melhores resultados segundo cada estado da natureza foram: para $\mathrm{e}_{1} \rightarrow \mathrm{a}_{2}=36$, para $\mathrm{e}_{2} \rightarrow \mathrm{a}_{3}=60$ e para $\mathrm{e}_{3} \rightarrow \mathrm{a}_{2}=48$. Esses valores caracterizam uma decisão a posteriori. A diferença entre valores da decisão a posteriori e valores da decisão a priori permitem estimar o valor em condições de informação perfeita, os quais, uma vez consideradas as respectivas ponderações, permitem calcular o Veip. (JOKUNG-NGUÉNA, 2001)

Quadro 15 - Estados da natureza e decisão

\begin{tabular}{|c|c|c|c|c|c|c|c|}
\hline \multicolumn{2}{|c|}{$\begin{array}{l}\text { Informação } \\
\text { possível }\end{array}$} & \multicolumn{2}{|c|}{$\begin{array}{l}\text { Decisão a priori } \\
\text { p/Pascal }\end{array}$} & \multicolumn{2}{|c|}{$\begin{array}{l}\text { Decisão a posteriori } \\
\text { p/ maiores valores }\end{array}$} & \multirow{2}{*}{$\begin{array}{c}\text { Valor da } \\
\text { informação perfeita } \\
\text { ou Valor do } \\
\text { arrependimento }\end{array}$} & \multirow{2}{*}{ Veip } \\
\hline Estado & $\begin{array}{l}\text { Probabi- } \\
\text { lidade }\end{array}$ & Decisão & $\begin{array}{l}\text { Resul- } \\
\text { tado }\end{array}$ & Decisão & $\begin{array}{l}\text { Resul- } \\
\text { tado }\end{array}$ & & \\
\hline$\left(e_{1}\right)$ & 0,25 & $a^{*}=a_{3}$ & -3 & $\mathrm{a}_{\mathrm{ind}(1)}=\mathrm{a}_{2}$ & 36 & 39 & \multirow{3}{*}{14,25} \\
\hline$\left(\mathrm{e}_{2}\right)$ & 0,50 & $a^{*}=a_{3}$ & 60 & $\mathrm{a}_{\mathrm{ind}(2)}=\mathrm{a}_{3}$ & 60 & 0 & \\
\hline$\left(\mathrm{e}_{3}\right)$ & 0,25 & $a^{*}=a_{3}$ & 30 & $\mathrm{a}_{\mathrm{ind}(3)}=\mathrm{a}_{2}$ & 48 & 18 & \\
\hline
\end{tabular}

Fonte: Adaptado de Jokung-Nguéna (2001).

Nesses termos, levando em consideração as ações que poderiam ter sido as melhores, caso fossem escolhidas em cada estado da natureza, o que caracteriza a condição de informação perfeita, pode-se concluir que o verdadeiro valor esperado é de \$14,25.

Quadro 16 - Ações possíveis e resultados por autores Síntese dos resultados em universo mensurável

\begin{tabular}{|c|c|c|c|c|c|}
\hline \multirow{2}{*}{ Critérios } & \multirow{2}{*}{$\begin{array}{c}\text { Pascal } \\
\text { Esperança } \\
\text { matemática }\end{array}$} & \multicolumn{2}{|c|}{ Markowitz } & \multirow{2}{*}{ Bernoulli } & \multirow{2}{*}{ Veip } \\
\hline & & $1^{\circ}$ Caso & $2^{\circ}$ Caso & & \\
\hline Outdoor $\left(\mathrm{a}_{1}\right)$ & 6 & 0,47 & $a_{3}$ se $\lambda<=0,93$ & 2,3475 & \multirow{3}{*}{14,25} \\
\hline Televisão $\left(\mathrm{a}_{2}\right)$ & 27 & 1,73 & $\begin{array}{c}a_{2} \text { se } 0,93<= \\
\lambda<=7,34\end{array}$ & 3,5178 & \\
\hline Jornais $\quad\left(a_{3}\right)$ & 36,75 & 1,41 & $a_{1}$ se $\lambda>=7,34$ & 3,5329 & \\
\hline
\end{tabular}

Fonte: Adaptado de Jokung-Nguéna (2001).

\subsection{A Utilidade Esperada de Von Neumann e Morgenstern}

A partir do trabalho de Bernoulli, a economia não parou de discutir sobre a possibilidade e pertinência da medida da utilidade. Nasce assim a dicotomia entre as proposições cardinal e ordinal. A primeira pretende medir a utilidade marginal em termos monetários; enquanto a segunda 
considera que a utilidade, por ser subjetiva, não pode ser medida, além de não haver necessidade dessa medida, de maneira que uma classificação da utilidade é suficiente para os propósitos analíticos. É nesse contexto que von Neumann e Morgenstern propõem um cálculo da utilidade e, ao mesmo tempo, apresentam os fundamentos axiomáticos da utilidade esperada.

É interessante lembrar que a teoria da utilidade esperada explica situações de risco, mas ao mesmo tempo contribuiu para resolver o paradoxo de São Petersburgo. O conhecimento das probabilidades dos eventos permite estimar situações de risco e incerteza através de mecanismos aleatórios. O risco é então avaliado pela frequência observável dos eventos, enquanto que a incerteza necessita de uma avaliação subjetiva do fenômeno; nesse momento, a experiência é um grande elemento que proporciona a realização dessa avaliação. (KAST, 1993)

Assim é que duas situações bem distintas podem ser consideradas como similares. A primeira é caracterizada pela existência de uma frequência, ou seja, com uma probabilidade objetiva (jogo de roleta). Enquanto a segunda não dispondo de frequência, trata-se de uma probabilidade subjetiva, como é o caso da corrida de cavalos em que o apostador acredita que a probabilidade de vitória é dada pela relação entre sua escolha e o inverso da quantidade total de cavalos na corrida. Dessa forma, desde que se possa construir uma distribuição de probabilidades sobre as consequências da decisão, risco e incerteza se confundem e podem ser avaliados.

Nesse momento, o fundamental é que em situações de risco, o comportamento de quem decide seja determinado por suas preferências sobre essas distribuições de probabilidades. Essas distribuições foram denominadas de loterias, mesmo que os resultados não sejam provenientes de experimentos aleatórios. Em situações como estas, o indivíduo é considerado como racional se escolhe uma ação com vistas à maximização da utilidade esperada da loteria sobre as consequências que correspondem a esta ação. É preciso, portanto, construir normas para a escolha das ações; de sorte que um comportamento racional é aquele que reconhece essas normas e toma uma decisão de maneira subordinada a um critério que as normas permitiram definir. (KAST, 1993)

Com o auxílio da matriz de resultados que vem sendo utilizada nos diversos critérios de decisão (Quadro 1), será apresentada uma regra de classificação das ações, que considere a utilidade esperada em um ambiente de aleatoriedade e probabilidade. (JOKUNG-NGUÉNA, 2001) Assim, considerando duas ações $\mathrm{a}_{\mathrm{k}}$ e $\mathrm{a}_{\mathrm{\prime}^{\prime}}$ é preciso saber em que condições a primeira é preferível à segunda em termos de utilidade. Para tanto, pode-se 
considerar que o conjunto de valores assumidos nas diferentes ações, em função dos estados da natureza, constitui um conjunto cardinal finito, o qual é chamado de conjunto $\mathrm{C}$ e tem a seguinte forma:

$$
\mathrm{C}=\left\{\begin{array}{l}
\mathrm{R}_{11} ; \mathrm{R}_{12} ; \mathrm{R}_{13} \\
\mathrm{R}_{21} ; \mathrm{R}_{22} ; \mathrm{R}_{23} \\
\mathrm{R}_{31} ; \mathrm{R}_{32} ; \mathrm{R}_{33}
\end{array}\right\}
$$

Este conjunto $C$ pode ser ordenado em um conjunto cardinal reduzido $C^{*}$, de maneira a se obter cada resultado apenas uma vez:

$$
C=\left\{c_{1}, c_{2}, c_{3}\right\}
$$

O princípio fundamental da teoria da utilidade esperada é que, em situação de risco, o comportamento de quem decide é inteiramente determinado por suas preferências de distribuições de probabilidades sobre as consequências de suas ações. Considerando que as escolhas são determinadas pelas preferências sobre as diferentes loterias, resultando ou não de uma experiência aleatória. Nessas circunstâncias, aquele que decide é considerado como racional se suas escolhas são coerentes com as preferências das loterias. Assim, se a ação (a) corresponde à loteria (I) e a ação $\left(\mathrm{a}^{\prime}\right)$ corresponde à loteria $\left(\mathrm{I}^{\prime}\right)$, então um agente racional escolherá (a) em lugar de ( $\left.\mathrm{a}^{\prime}\right)$ se ele prefere (l) em vez de ( $\left.\mathrm{I}^{\prime}\right)$. Nesse contexto, é preciso que se disponha de uma definição para a relação de preferência no conjunto das probabilidades. Isso fica garantido pelos axiomas de von Neumann e Morgenstern.

\section{Axiomas da Teoria da Utilidade Esperada}

Os axiomas expressam as condições em que as preferências devem ser verificadas para que possam ser representadas por uma função numérica. Seguindo os passos de Jokung-Nguéna (2001), os quatro axiomas da utilidade esperada são apresentados.

1. Axioma da comparabilidade

$$
\forall p, q \in P \text { seja } p \succ q \text {; seja } q \succ p ; \text { seja } p \sim q
$$

Este axioma representa o fato de que duas distribuições sempre podem ser comparáveis. 
2. Axioma da transitividade

$\forall p, q, r \in P$ si $p \succ q$ e $q \succ r$, então $p \succ r$

Este axioma representa a racionalidade pura que conduz ao estabelecimento de uma coerência entre as classificações.

1. Axioma de continuidade ou do equivalente certo

$$
\forall p, q, r \in P \text { si } p \succ q \succ r \text { então }\left\{\begin{array}{l}
\exists \alpha \beta \in[0,1] \text { tal que } \\
\alpha p+(1-\alpha) r \succ q \succ \beta p+(1-\beta) r
\end{array}\right\}
$$

Esse axioma guarda uma analogia com o princípio de Arquimedes. Com efeito, quais sejam os reais positivos $(z)$ e ( $\left.z^{\prime}\right)$, existe sempre um inteiro natural $(k)$ tal que $k z \geq z^{\prime}$, mesmo que o primeiro número real seja muito pequeno e o segundo seja muito grande. Assim, uma terceira loteria localizada entre essas duas sempre poder ser dominada (respectivamente dominar) por outra que tenha como resultado as duas primeiras. O axioma da continuidade indica, portanto, que para toda e qualquer perspectiva aleatória, sempre existe um rendimento certo que se encontra entre as situações aleatórias menos e mais favoráveis.

1. Axioma da independência forte ou de substituição

$\forall p, q, r \in P ; \forall \alpha \in[0,1]$ si $p \succ q$ então $\alpha p+(1-\alpha) r \succ \alpha q+(1-\alpha) r$

Este axioma mostra que a introdução de distribuições nas loterias não modifica, em nenhum caso, as preferências. Esse axioma pode ser interpretado como segue:

$$
\text { Si } p \succ q \text { então } L(p, r ; \alpha, 1-\alpha) \succ L(q, r ; \alpha, 1-\alpha)
$$

A atitude de uma pessoa diante de duas loterias deve apenas depender de sua atitude em face de (p) e (q) e não da maneira de obter (p) ou (q) por meio dessas loterias.

O axioma da independência é muito particular para a teoria da utilidade esperada. Ele permite observar que a ordem das preferências entre duas loterias, digamos $L_{1}$ e $L_{2}$, não se altera, mesmo quando cada uma delas é combinada em uma mesma proporção com uma terceira loteria, $L_{3}$. Combinar uma loteria com outra constitui uma operação muito diferente da adição de duas variáveis. Assim, caso os montantes sejam elevados, 
pode induzir as pessoas a revisar a ordem de suas preferências, levando a crer que essas pessoas deixam de ser agentes racionais.

\section{I Comportamento Quanto ao Risco}

A teoria da utilidade esperada explica as diferentes atitudes face ao risco. Nessas circunstâncias, as pessoas apresentam comportamentos diferenciados, algumas enfrentam com maior facilidade essas situações, outras se mostram neutras e outras ainda são menos inclinadas ao risco. Os axiomas da teoria da utilidade esperada permitem a construção de uma função de utilidade, a qual será de grande interesse para compreender os comportamentos das pessoas face ao risco, tornando mais precisos os sentimentos de aversão ou de propensão ao risco que normalmente as pessoas sentem.

Para essa teoria, uma pessoa é avessa ao risco se, em qualquer loteria, ela prefere o valor de um rendimento esperado com certeza, ao invés de participar da loteria, mesmo com alguma probabilidade de ganhar mais, isso porque não se sabe qual será o desfecho em termos de estado da natureza. Essa pessoa prefere, portanto, o valor esperado de um rendimento em lugar de apostar um rendimento mais elevado, mas ao mesmo tempo correr o risco de receber um rendimento menos elevado que o esperado. Uma situação de aversão ao risco pode ser mais bem esclarecida com o auxílio do gráfico a seguir.

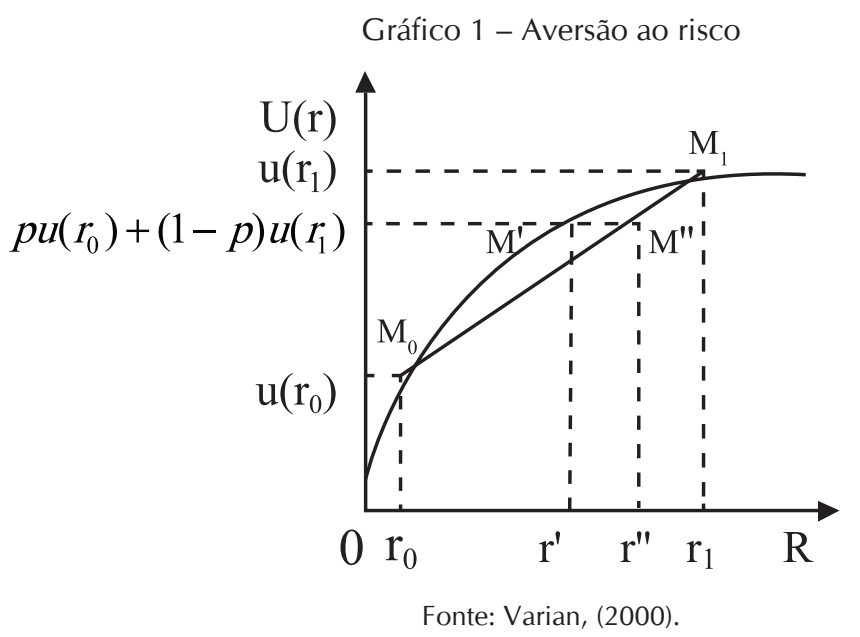

Vol. V - no 9 - dezembro de 2011 
Assim, em uma perspectiva aleatória R detém dois elementos: $\left(p, r_{0}\right)$ e $\left((1-p), r_{1}\right)$. O valor da utilidade esperada do rendimento $r^{\prime}$ é dado por $r=p u\left(r_{0}\right)+(1-p) u\left(r_{1}\right)$, tal como aparece na ordenada de $\mathrm{M}^{\prime}$, enquanto que o rendimento esperado é caracterizado pelo ponto $r$, tal como mostra $M$ sobre o segmento de reta $M_{0}$ e $M_{1}$ do gráfico. Como a curva de utilidade é côncava, já que ela é positivamente relacionada com o rendimento, mas isso acontece a taxas decrescentes, condicionando $r^{\prime}<r^{\prime \prime}$, de maneira que o rendimento certo corresponde àquele que possibilita o mesmo nível de utilidade esperada, considerando a condição de aleatoriedade.

Dessa forma, uma pessoa racional naturalmente irá preferir um seguro em lugar de uma loteria, mesmo que essa loteria seja justa, logo ela irá também preferir pagar por esse seguro um valor correspondente a um máximo de $r^{\prime \prime}-r^{\prime}$ para garantir o rendimento $r^{\prime}$, ou seja, $r^{\prime \prime}-r^{\prime}$ constitui o prêmio de risco dessa pessoa. Esse rendimento $r^{\prime}$, também chamado de equivalente certo, depende das probabilidades e dos próprios rendimentos, mas não depende dos estados da natureza; de maneira que uma nova composição dos rendimentos entre diferentes estados da natureza, que mantenha o mesmo rendimento equivalente certo, não modifica as escolhas. (GUERRIEN; NEZEYS, 1987)

Pode-se então concluir que uma pessoa avessa ao risco considera que o valor da utilidade esperada de sua loteria é mais elevado que o valor esperado da própria loteria. Em sentido oposto, tem-se uma pessoa propensa ao risco, ou seja, uma pessoa que prefere a loteria incerta em lugar da utilidade de sua loteria, por essa razão seu prêmio de risco é negativo, logo ela está disposta a pagar para participar dessa loteria. Quando esses valores são iguais, pode-se afirmar que se trata de uma pessoa neutra em relação ao risco, de maneira que o prêmio de risco dessa pessoa é zero.

\subsection{Avaliação Empírica da Teoria da Utilidade Esperada}

Retomando a Quadro 2 em que possíveis resultados são apresentados, segundo as ações e os estados da natureza, pode-se proceder a uma avaliação empírica da teoria da utilidade esperada. (JOKUNG-NGUÉNA, 2001) 
Quadro 17 - Ações possíveis por níveis da concorrência

\begin{tabular}{|c|c|c|c|}
\hline \multirow{2}{*}{ Ações } & \multicolumn{3}{|c|}{ Níveis da Concorrência } \\
\cline { 2 - 4 } & $\begin{array}{c}\text { Fraca }\left(\mathrm{e}_{1}\right) \\
\mathrm{p}=0,25\end{array}$ & $\begin{array}{c}\text { Média }\left(\mathrm{e}_{2}\right) \\
\mathrm{p}=0,5\end{array}$ & $\begin{array}{c}\text { Forte }\left(\mathrm{e}_{3}\right) \\
\mathrm{p}=0,25\end{array}$ \\
\hline Outdoor $\left(\mathrm{a}_{1}\right)$ & 12 & -6 & 24 \\
\hline Televisão $\left(\mathrm{a}_{2}\right)$ & 36 & 12 & 48 \\
\hline Jornais $\left(\mathrm{a}_{3}\right)$ & -3 & 60 & 30 \\
\hline
\end{tabular}

Fonte: Adaptado de Jokung-Nguéna (2001).

Ordenando esses resultados de maneira crescente, chega-se ao conjunto cardinal:

$$
C^{*}=\{-6,-3,12,24,30,36,48,60\}
$$

Introduzindo as respectivas probabilidades nas ações, tem-se:

$$
\begin{aligned}
& a_{1}=L(-6,-3,12,24,30,36,48,60 ; 1 / 2,0,1 / 4,1 / 4,0,0,0,0) \\
& a_{2}=L(-6,-3,12,24,30,36,48,60 ; 0,0,1 / 2,0,0,1 / 4,1 / 4,0) \\
& a_{3}=L(-6,-3,12,24,30,36,48,60 ; 0,1 / 4,0,0,1 / 4,0,0,1 / 2)
\end{aligned}
$$

Uma representação mais simplificada permite dizer que:

$$
\begin{aligned}
& a_{1}=L\left(C^{*}, p_{1}\right) \\
& a_{2}=L\left(C^{*}, p_{2}\right) \\
& a_{3}=L\left(C^{*}, p_{3}\right)
\end{aligned}
$$

Que podem ser consideradas como loterias, as quais devem ser ordenadas em termos de preferências. Trata-se, portanto, de loterias que apresentam os mesmos resultados, ou seja, os elementos de C* são os mesmos, havendo uma diferenciação nas distribuições de probabilidades (p), as quais podem ser consideradas através dos pares $\left(p^{(k)}\right.$ e $\left.p^{(l)}\right)$ e representadas por:

$$
L\left(C ; p^{(k)}\right) \text { e } L\left(C ; p^{(l)}\right)
$$

Considerar que $\mathrm{a}_{\mathrm{k}}$ é preferível à $\mathrm{a}_{1}$ é o mesmo que dizer que $\mathrm{p}^{(\mathrm{k})}$ é preferível à $\mathrm{p}^{(\mathrm{l})}$. Como a classificação para o conjunto das ações $\mathrm{A}$ é isomorfa em relação à classificação no interior do conjunto de distribuições de probabilidade, tem-se que: 


$$
P=\left\{p^{1}, p^{2}, p^{3}, \ldots, p^{m}\right\}
$$

O quadro, contendo os resultados e suas respectivas probabilidades, permite estimar os resultados de uma utilidade esperada. Para tanto, considerou-se uma função de utilidade na forma de $u(w)=\ln (10+W)$. O valor 10 introduz uma transformação linear na função de utilidade que permite contornar a existência de números negativos que inviabilizam o cálculo do logaritmo neperiano.

Quadro 18 - Ações possíveis por níveis da concorrência e da variância e utilidade esperada

\begin{tabular}{|c|c|c|c|c|}
\hline \multirow{2}{*}{ Ações } & \multicolumn{3}{|c|}{ Níveis da Concorrência } & \multirow{2}{*}{ UE } \\
\cline { 2 - 4 } & $\begin{array}{c}\text { Fraca }\left(\mathrm{e}_{1}\right) \\
\mathrm{p}=0,25\end{array}$ & $\begin{array}{c}\text { Média }\left(\mathrm{e}_{2}\right) \\
\mathrm{p}=0,5\end{array}$ & $\begin{array}{c}\text { Forte }\left(\mathrm{e}_{3}\right) \\
\mathrm{p}=0,25\end{array}$ & \\
\hline Outdoor $\left(\mathrm{a}_{1}\right)$ & 0,7728 & 0,6931 & 0,8816 & 2,3475 \\
\hline Televisão $\left(\mathrm{a}_{2}\right)$ & 0,9572 & 1,5455 & 1,0151 & 3,5178 \\
\hline Jornais $\left(\mathrm{a}_{3}\right)$ & 0,4865 & 2,1242 & 0,9222 & 3,5329 \\
\hline
\end{tabular}

Fonte: Adaptado de Jokung-Nguéna (2001).

Dessa forma, pelo critério da utilidade esperada pode-se concluir que a escolha ótima corresponde à publicidade realizada através de jornais (ação $a_{3}$ ), pois esse é o resultado que proporciona o mais elevado grau da função de utilidade esperada. Esse critério ainda permite dizer que as estratégias devem obedecer à seguinte ordem: $a_{3} \succ a_{2} \succ a_{1}$.

\section{3 Índices de Aversão ao Risco}

Em duas publicações independentes e próximas no tempo, Pratt e Arrow propuseram definições bem similares ${ }^{9}$ para a aversão ao risco, bem como para o aumento dessa aversão. A partir do conceito de prêmio de risco foi montada a fórmula celebre da medida do risco, a qual ficou vinculada na literatura econômica ao nome dos dois autores - a fórmula Arrow-Pratt. O prêmio de risco, como já exposto, é o montante de riqueza que o indivíduo abre mão, para manter a certeza de um resultado diante de uma loteria. A loteria apresenta uma visão estatística do risco (medida pela variância), enquanto que o prêmio de risco representa a subjetividade

\footnotetext{
${ }^{9}$ Em verdade, J. Pratt em 1964 e K. Arrow em 1965 propuseram definições diferenciadas de um ponto de vista eminentemente literário, mas que se mostraram equivalentes de um ponto de vista matemático. (EECKHOUDT, 2001)
} 
do indivíduo em relação ao risco (medida pela concavidade da função de utilidade).

Assim, uma vez caracterizada a concavidade da função de utilidade (U), pode-se imaginar um indivíduo possuindo uma dada riqueza inicial $\left(\mathrm{W}_{0}\right)$, a qual será posta em uma loteria aditiva $(X)$ de esperança $E(X)$. O prêmio de risco associado a essa loteria sendo dado por $\Pi$, pode-se estimar o resultado final por:

$$
\mathrm{E}\left[\mathrm{U}\left(\mathrm{W}_{0}+\tilde{\mathrm{X}}\right)\right]=\mathrm{U}\left(\mathrm{W}_{0}+\mathrm{E}(\tilde{\mathrm{X}})-\Pi\right)
$$

Nessas condições, Arrow e Pratt estimaram medidas locais de risco. Considerando uma função de utilidade $U$, tem-se que $U^{\prime}$ e $U^{\prime \prime}$ são as derivadas primeira e segunda da função de utilidade em relação à riqueza (x). Como a função de utilidade é côncava (crescente a taxas decrescentes), significa dizer que $U(x)>0$ e $\mathrm{U}^{\prime \prime}(\mathrm{x})<0$. A primeira derivada garante a concavidade e a segunda garante a aversão ao risco.

Quanto maior a concavidade da curva de utilidade maior será a aversão ao risco, de maneira que a derivada segunda dessa função, embora não constitua um bom indicador para uma medida do risco ${ }^{10}$ fornece, por meio de seus sinais, informações para se estimar o grau dessa aversão. Uma função de utilidade diferençável duas vezes pode apresentar as seguintes possibilidades de derivada segunda: $U^{\prime \prime}(x) \leq 0$, em que o sinal negativo expressa a aversão ao risco; $U^{\prime \prime}(x)=0$, expressa a neutralidade quanto ao risco e $U^{\prime \prime}(x) \geq 0$, em que o sinal positivo expressa a propensão ao risco.

A solução encontrada por Pratt consistiu em estabelecer um índice absoluto de aversão ao risco através da normalização da derivada segunda da função de utilidade pela derivada primeira. (VARIAN, 2000) O índice absoluto de aversão ao risco é então dado por:

$$
\mathrm{r}(\mathrm{x})=-\frac{\mathrm{U}^{\prime \prime}(\mathrm{x})}{\mathrm{U}^{\prime}(\mathrm{x})}
$$

Esse coeficiente permite afirmar que uma pessoa com um índice absoluto de aversão ao risco igual a $r(x)$ tem mais aversão que outra, cujo índice é $r^{\prime}(x)$, se $r(x)<r^{\prime}(x)$ Ademais, possuir informação sobre um determinado índice de aversão possibilita o conhecimento da função de utilidade, basta proceder a uma dupla integração. Como as constantes de integração caracterizam transformações lineares das funções de utilidade, o que se espera é que elas não alterem as preferências.

\footnotetext{
${ }^{10}$ Multiplicando a função de utilidade esperada por uma constante k não se altera o comportamento do consumidor, no entanto, afeta a medida da aversão ao risco, ou seja, modifica a medida do risco; dessa forma, o uso da derivada segunda como medida do risco fica problematizado.
} 
Com esse resultado, é possível realizar a estimativa do prêmio de risco, chegando-se ao seguinte resultado:

$$
\Pi=\frac{\sigma_{\sim}^{2}}{2}\left(-\frac{\mathrm{U}^{\prime \prime}(\mathrm{x})}{\mathrm{U}^{\prime}(\mathrm{x})}\right)
$$

Ou seja, o prêmio de risco é o resultado do produto da metade da variância da loteria pelo índice absoluto de aversão ao risco.

\section{Os Paradoxos da Utilidade Esperada}

Em 1953, Allais expõe uma contradição presente no princípio da utilidade esperada de von Neumann e Morgenstern, sobretudo no que diz respeito ao axioma da independência. Esse fundamento seerá a seguir exposto.

\section{I Paradoxo de Allais}

Esse axioma permitiu afirmar que as preferências dos indivíduos entre duas loterias não devem se modificar quando elas são combinadas nas mesmas proporções com uma terceira loteria. Dessa forma, a ordem das preferências não deveria se modificar quando sofrem modificações neutras. Isso permitiria afirmar que as preferências relativas aos ganhos devem ser estáveis, quais sejam as probabilidades desses ganhos.

Mas o que se verifica, em verdade, é que as pessoas acabam por modificar a ordem de suas preferências quando as probabilidades de receber esses ganhos se modificam, principalmente quando esses ganhos deixam de ser certos para serem hipotéticos. Para provar esse paradoxo, Allais apresenta duas loterias, as quais foram construídas para mostrar que o axioma da independência não é respeitado, refutando, por conseguinte esse axioma, verdadeiro pilar da tese das utilidades esperadas.

A prova desse argumento consistiu em apresentar duas opções a diferentes pessoas, cada uma dessas opções se decompõe em duas loterias. Nessas condições, solicita-se que essas pessoas revelem suas preferências.

\section{Opção 1}

$\mathbf{L}_{\mathbf{A}}:$ receber $\$ 100$ com certeza.

$\mathrm{L}_{\mathbf{B}}$ : receber $\$ 500$ com probabilidade de $10 \%$, receber $\$ 100$ com probabilidade de $89 \%$ e nada receber com probabilidade de $1 \%$. 


\section{Opção 2}

$\mathbf{L}_{\mathbf{C}}$ : receber $\$ 100$ com probabilidade de $11 \%$.

$\mathbf{L}_{\mathbf{D}}$ : receber $\$ 500$ com probabilidade de $10 \%$ e nada receber com probabilidade de $90 \%$.

Com essas opções existem quatro possibilidades de escolas: $\left(L_{A}, L_{C}\right)$ , $\left(L_{A}, L_{D}\right),\left(L_{B}, L_{C}\right)$ e $\left(L_{B}, L_{D}\right)$, no entanto apenas as possibilidades $\left(L_{A}, L_{C}\right)$ e $\left(L_{B}, L_{D}\right)$ são compatíveis com o axioma de independências de von Neumann e Morgenstern. Mas, não raramente, as pessoas escolhem as loterias $\left(L_{A}, L_{D}\right)$ e $\left(L_{B}, L_{C}\right)$, escolhas essas que entram em contradição com esse axioma. Segundo Kahneman e Tversky (1979), 80\% das pessoas preferem LA em lugar de LB, mas $65 \%$ das pessoas preferem LD em vez de LC. No entanto, se a escolha na opção 1 foi LA é porque $U\left(L_{A}\right)>U\left(L_{B}\right)$ para quem fez a escolha; da mesma forma, se a escolha na opção 2 foi LD é porque $U\left(L_{D}\right)>U\left(L_{C}\right)$. Mas esses resultados entram em contradição com a lógica interna do axioma de independência do modelo de utilidade esperada de von Neumann e Morgenstern.

Calculando as utilidades esperadas das duas opções de loterias, pode-se visualizar melhor a contradição referida:

\section{Opção 1}

$\mathrm{UEL}_{\mathrm{A}}: U E(100)(1,0)=U E(100)$
$\mathrm{UEL}_{\mathbf{B}}: \quad U E(500)(0,10)+U E(100)(0,89)+U E(0)(0,01)=U E(139)$

\section{Opção 2}

$$
\begin{aligned}
& \mathrm{UEL}_{\mathrm{c}}: U E(100)(0,11)=U E(11) \\
& \mathrm{UEL}_{\mathrm{D}}: U E(500)(0,10)+U E(0)(0,90)=U E(50)
\end{aligned}
$$

Com um pequeno arranjo, pode-se demonstrar que LC e LD são respectivamente transformações lineares de LA e LB, tal como pode ser visto abaixo:

$$
\begin{aligned}
& L_{C}=L_{A}-(101)(0,89)+(1)(0,89)=100-(101)(0,89)+(1)(0,89)=11 \\
& L_{D}=L_{B}-(101)(0,89)+(1)(0,89)=139-(101)(0,89)+(1)(0,89)=50
\end{aligned}
$$


Em tese, uma transformação linear introduzida nas loterias não deve provocar alteração na ordem das escolhas, de sorte que escolher LA na opção 1 deveria implicar necessariamente na escolha de LC na opção 2, o que não ocorre com a maior parte das pessoas. Dessa forma, segundo Pradier (2006), resta apenas uma das observações a seguir:

1. Os indivíduos não estariam decidindo de acordo com a teoria. Nesse caso, eles não estariam se comportando de maneira racional;

2. Os indivíduos estariam, de maneira estatisticamente significativa, violando uma condição teórica, provavelmente porque a teoria estaria impondo restrições não racionais. Nesse caso, a própria teoria não seria racional.

Uma explicação para esse paradoxo é que, provavelmente as pessoas foquem a certeza do resultado na opção 1 , ao invés de correr o risco de nada ganhar, ainda que isso ocorra com uma probabilidade muito pequena $(1 \%)$. Por outro lado, elas estariam focando nos possíveis ganhos, $\$ 500$ contra \$100. (MOUREAU; RIVAUD-DANSET, 2004)

\subsection{Paradoxo de Ellsberg}

O paradoxo de Ellsberg, apresentado em 1961, se contrapõe à utilidade esperada de Savage e à representação da informação sob a forma de probabilidade. A apresentação do raciocínio se dá com o auxílio de uma urna contendo 90 bolas. Sabe-se que do total dessas bolas 30 são vermelhas e 60 brancas ou pretas em proporção desconhecida. Propõe-se então um jogo com duas tiragens, cujas apostas e os ganhos aparecem no quadro a seguir.

Quadro 19 - Ações possíveis por tiragem

\begin{tabular}{|c|c|c|c|c|c|c|c|}
\hline \multicolumn{4}{|c|}{ Primeira tiragem } & \multicolumn{4}{c|}{ Segunda tiragem } \\
\hline Aposta & Vermelha & Branca & Preta & Aposta & Vermelha & Branca & Preta \\
\hline A1 & 100 & 0 & 0 & A 3 & 100 & 0 & 100 \\
\hline A2 & 0 & 100 & 0 & A 4 & 0 & 100 & 100 \\
\hline
\end{tabular}

Fonte: Adaptado de Moureau e Rivaud-Danset (2004).

A aposta 1 permite ganhar 100 se a bola for vermelha e a aposta 2 permite ganhar 100 se a bola for branca. Por outro lado, a aposta 3 ganha 100 se a bola for vermelha ou preta e a aposta 4 ganha 100 se a bola for branca ou preta. 
Diante dessas tiragens, quatro combinações são possíveis: (1 e 3), ( 1 e 4), ( 2 e 3 ) e ( 2 e 4). Mas apenas as combinações ( 1 e 3) e (2 e 4) são compatíveis com o axioma de Savage. No entanto, as combinações (1 e 4) são as mais escolhidas, o que coloca uma contradição para o teorema de Savage. Se $A_{1}$ foi escolhida é porque a probabilidade de sair uma bola vermelha foi vista como mais elevada que a probabilidade de sair uma bola branca. Por outro lado, se $\mathrm{A}_{4}$ foi escolhida é a probabilidade de sair uma bola branca ou uma bola preta vermelha foi vista como mais elevada que a probabilidade de sair uma bola vermelha ou preta.

Os resultados das duas tiragens, portanto, são:

Tiragem 1: $p(V) \geq p(B)$

Tiragem 2: $p(B)+p(P) \geq p(V)+p(P)$

Basta eliminar $\mathrm{p}(\mathrm{P})$ dos dois lados, chega-se facilmente a $p(B) \geq p(V)$, o que contradiz a Aposta 1 e caracteriza a existência de um paradoxo.

Com esse paradoxo pode-se questionar o princípio da coisa certa aplicado a uma situação de incerteza. (KAST, 1993) Nesse momento, a medida aditiva em que a probabilidade da reunião de dois conjuntos disjuntos, cujo resultado é a soma de suas probabilidades, não pode ser aplicada ao exemplo acima. Isso tem conduzido ao estudo de outras formas de ponderação das probabilidades relativas a problemas de decisão.

\subsection{A Teoria das Perspectivas}

Além dos paradoxos de Allais e Ellsberg, outras críticas colocam dificuldades lógicas para a teoria da utilidade esperada de von Neumann e Morgenstern. Kahneman e Tversky (1979) se encontram nesse rol, com sua teoria das perspectivas (Prospect Theory). Para esses autores, muitas decisões sobre acontecimentos incertos são baseadas em crenças relativas às probabilidades, as quais podem expressar as probabilidades subjetivas de maneira numérica. Daí a necessidade de se saber como essas crenças podem ser determinadas e avaliadas em um processo de decisão.

Para entender como as crenças são determinadas, antes de tudo, é preciso saber que as pessoas normalmente se guiam a partir de certo número limitado de regras e métodos (heurísticas), que auxiliam na descoberta de soluções a problemas enfrentados em condições de incerteza. Trata-se de regras e métodos que, embora não sejam rigorosos de um ponto de vista científico, acabam por refletir o conhecimento que as pessoas têm do problema, de maneira que contribui na obtenção de uma solução 
perfeitamente satisfatória. Dessa forma, tarefas tidas como complexas podem ser simplificadas, a ponto de possibilitar uma melhor compreensão do problema e, portanto facilitar uma decisão. $\mathrm{O}$ uso de métodos e regras facilitadores é muito comum, ainda que normalmente contribuam para a formação de vieses sistemáticos que distorcem o tratamento da informação. Esses vieses naturalmente distorcem os julgamentos que se possa ter sobre os problemas e, dado que eles não são aleatórios, requerem cuidados especiais na medida em que podem condicionar determinismos de julgamentos onde não deveriam existir. São três os tipos de métodos e regras que as pessoas mais usam na classificação de fenômenos: representatividade, disponibilidade e ajustamento. (TVERSKY; KAHNEMAN, 1974)

A representatividade permite avaliar qual a similaridade existente entre os eventos A e B. Se o grau de similaridade é elevado, pode-se imaginar que $A$ é representativo de $B$, logo a probabilidade que $A$ seja proveniente de B é também elevada, caso contrário essa probabilidade é baixa. Exemplo: João tem 32 anos, possui escolaridade universitária, é casado e tem dois filhos. João é muito estimado pelos vizinhos, que o considera uma pessoa muito motivada para o trabalho, apesar de ser reservada e altruísta, ele se interessa muito pelos problemas políticos e sociais. Qual a probabilidade de João ser um advogado? Através da representatividade pode-se responder afirmativamente a essa questão, ainda que seja com um grau muito elevado de incerteza, caso João se encaixe bem no estereótipo de advogado. Probabilidade e similaridade devem então andar juntas para a maior parte das pessoas, mesmo que a incerteza conduza a erros sistemáticos.

A disponibilidade dessas situações caracteriza a facilidade com que casos semelhantes ao analisado possam ser lembrados, de maneira a permitir uma classificação rápida. Exemplo: José sente dores localizadas no peito com radiações pelo braço. Sabendo que José tem entre 40 e 50 anos, uma faixa etária em que os acidentes cardiovasculares apresentam uma incidência muito elevada de mortes, qual a probabilidade de João sobrevier? O conhecimento que se dispõe para esse tipo de ocorrência passa a ser aplicado de maneira imediata ao caso de João. A confiança e a disponibilidade da informação permitem o aparecimento de vieses sistemáticos, colocando a correlação estabelecida em uma condição bastante ilusória. Nesse momento a probabilidade subjetiva fica influenciada pela informação que se dispõe.

O ajustamento permite que as pessoas partam de um valor de referência (ponto inicial ou âncora) e vão modificando sua classificação em função de novas estimativas; dessa forma, sistematicamente elas podem 
revisar suas avaliações a partir de informações mais atualizadas. O valor de referência permite a formulação do problema, bem como pode ser o resultado de uma avaliação parcial. Como pontos de partida diferenciados permitem resultados distintos, fica evidente que a formação de vieses é muito forte. Exemplo: Dois grupos de pessoas A e B encontram-se diante de um desafio. $O$ grupo $A$ dispõe de apenas cinco segundos para responder a seguinte questão $8 \times 7 \times 6 \times 5 \times 4 \times 3 \times 2 \times 1$; enquanto que o grupo $\mathrm{B}$ também dispondo de exatos cinco segundos deve responder à questão $1 \times 2 \times 3 \times 4 \times 5 \times 6 \times 7 \times 8$. Qual grupo deve se aproximar mais da resposta correta? Os dois grupos oponentes podem efetuar cálculos, realizar extrapolações e ajustamentos, mesmo sabendo que no exíguo espaço de tempo esses procedimentos são insuficientes para se alcançar uma resposta definitiva e correta. A maior parte das pessoas opta pelo grupo A, quando a operação é a mesma e o resultado é igual, mas a sequencia descendente tem se mostrado mais frutuosa para a mente humana, de sorte que o ponto oito como referência inicial se mostra mais pertinente.

Assim, com experimentos e respostas às regularidades comportamentais, podem-se descrever várias classes de problemas de escolha em que as preferências violam sistematicamente os axiomas da teoria de utilidade esperada. Diante disso, esses autores observam que a teoria da utilidade esperada, como é vulgarmente interpretada e aplicada, não constitui um modelo descritivo adequado, ao tempo em que propõem um quadro analítico alternativo para avaliar as escolhas em condições de risco. (KAHNEMAN; TVERSKY, 1979) Para tanto, esses autores deduzem alguns efeitos complexos provenientes do comportamento das pessoas em situações que envolvem risco e incerteza. São três os principais efeitos: efeito certeza, efeito espelho e efeito construção. (MOUREAU; RIVAUD-DANSET, 2004)

O efeito certeza resulta da diferença entre um ganho certo e um ganho provável, esse efeito é, sem dúvida, muito mais importante que uma diferença comparável em uma série de probabilidades intermediárias, tal como exposto pelo teorema da continuidade da teoria da utilidade esperada. Esse efeito introduz um viés no processo de escolha, o qual proporciona uma verdadeira transgressão aos axiomas dessa teoria.

Com uma similaridade muito forte com paradoxo de Allais, esse efeito pode ser apresentado a partir de duas questões.

1. Qual deve ser a preferências entre duas possibilidades de escolha (A e B). A escolha A apresenta um ganho de $\$ 4.000$ com $80 \%$ de probabilidade e a escolha B apresenta um ganho certo de $\$ 3.000$. 
2. Qual deve ser a preferência entre duas possibilidades de escolha (C e D). A escolha C apresenta um ganho de $\$ 4.000$ com $20 \%$ de probabilidade e a escolha D apresenta um ganho de $\$ 3.000$ com $25 \%$ de probabilidade.

A opção A apresenta um valor esperado mais elevado que a opção B (\$3.200 contra \$3.000); da mesma forma a opção C apresenta um valor esperado também mais elevado que a opção $D(\$ 800$ contra $\$ 750)$. As escolhas deveriam, portanto, recair sobre as opções A e C, no entanto a maior parte das pessoas escolhe $\mathbf{B}$ e $\mathbf{C}$. Sem dúvida, trata-se de um comportamento paradoxal, na medida em que inverte a ordem das preferências, quando a questão 2 apenas representa uma transformação linear da questão 1. Com efeito, a questão 2 constitui nada mais que um percentual de $25 \%$ da questão 1 . Esse fato não deveria permitir tal inversão das escolhas, pode-se então concluir que o comportamento da maior parte das pessoas se mostra incongruente com a lógica matemática e incompatível com os axiomas da teoria da utilidade esperada.

Partindo de um princípio de que as pessoas não agem de maneira irracional, faz-se necessário uma explicação para tal inversão de comportamento. A resposta se encontra na psicologia de um processo de decisão em condições de risco e incerteza. Assim, quando a probabilidade de ganhar se torna muito pequena, as pessoas decidem mais pela dimensão do montante envolvido que pela probabilidade que envolve esse ganho. O efeito certeza considera, portanto, que a sensibilidade das pessoas quanto às probabilidades não é linear. Ademais, as preferências podem perfeitamente ser formadas no curso do próprio processo de decisão, de maneira que elas não existem a priori no espírito das pessoas. (GOLLIER; HILTON; RAUFASTE, 2003)

O efeito espelho decorre de um comportamento diferenciado em relação a um ganho e a uma perda. Normalmente as pessoas preferem um ganho certo ao incerto, mas elas também preferem uma perda hipotética em lugar de uma certeza de perda, isso porque a esperança de uma perda hipotética é mais elevada que uma perda garantida. Dessa forma, as pessoas se colocam como aptas para enfrentar riscos em jogos, mesmo quando têm consciência que esses jogos podem impor perdas, em média, mais elevadas que as perdas certas.

Uma inversão dos valores de ganho do exemplo anterior permite entender melhor esse efeito. Assim, a opção A se transforma em uma perda de $\$ 4.000$ com probabilidade de $80 \%$, enquanto que a opção B passa a considerar uma perda certa de $\$ 3.000$. Por outro lado, a opção $C$ se trans- 
forma em uma perda de $\$ 4.000$ com $20 \%$ de probabilidade e a opção D representa uma perda de $\$ 3.000$ com probabilidade de $25 \%$. Nesse novo ambiente as estimativas de valor esperado se apresentam da seguinte forma: opção A tem um valor esperado menor que a opção B (-\$3.200 contra -\$3.000); da mesma forma, a opção $C$ tem um valor esperado menor que a opção D (-\$800 contra $-\$ 750)$. No entanto, as escolhas mais frequentes recaem sobre as opções $\mathbf{A} \mathbf{e} \mathbf{D}$, fato esse que mantém a incongruência com os axiomas teóricos da utilidade esperada, isso porque a lógica matemática recomenda que as escolhas se fixem nas opções B e D.

Gráfico 2 - A função de utilidade segundo Tversky e Kahneman

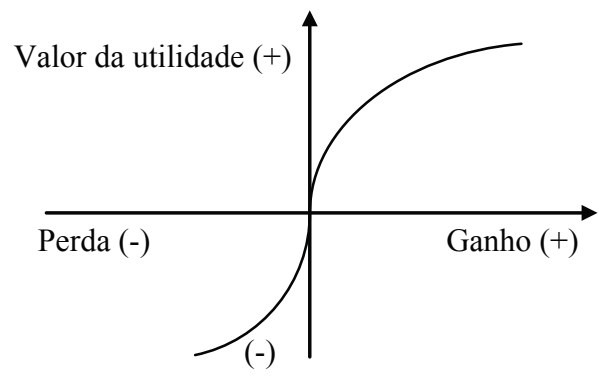

Fonte: Tversky e Kahneman (1974).

Uma interpretação possível desse fato consiste em dizer que houve uma sobreponderação da perda garantida. O efeito espelho fica então caracterizado, pelo fato de as pessoas apresentarem uma aversão à incerteza diante de ganhos e uma preferência em face das perdas. Dessa forma, as pessoas costumam minimizar muito mais as probabilidades das perdas que a propensão ao risco. Essa conclusão permite desenhar uma curva de valor da utilidade na forma de $\mathrm{S}$, tal como mostra o gráfico acima.

Essa função é geralmente côncava para ganhos potenciais e, convexa para perdas também potenciais, bem como ela é mais íngreme para pendas que para ganhos, além de se mostrar mais íngreme no ponto de referência. (KAHNEMAN; TVERSKY, 1979) Essa função requer uma comparação das perdas e/ou ganhos com uma referência. As pessoas raciocinam muito mais em relação a esse ponto, que em relação ao resultado líquido final do fenômeno. Como a função de valor da utilidade é côncava para ganhos e convexa para perdas, é natural que a referência seja frequentemente considerada no ponto zero do gráfico, ao qual se passou a denominar status quo. ${ }^{11}$ (EBER; WILLINGER, 2005) A concavidade e convexidade,

${ }^{11}$ A função de valor da utilidade da teoria das perspectivas assume a existência de uma descontinuidade 
representando utilidade marginal decrescente para ganhos e utilidade marginal crescente para perdas, podem ser expressas por $u^{\prime}(x) \leq 0$ para $x \geq 0$ e $u^{\prime}(x) \geq 0$ para $x \leq 0$.

A função de utilidade se apresenta mais inclinada para perdas relativamente aos ganhos. Isso denota que as pessoas são mais sensíveis em relação às perdas que aos ganhos. Assim, em termos absolutos, a desutilidade de perder um determinado valor é maior que a utilidade de ganhar esse mesmo valor, de maneira que $u^{\prime}(X)<u^{\prime}(-X)$ para todo e qualquer x. (EBER; WILLINGER, 2005) Assim, as pessoas são normalmente avessas ao risco para os ganhos e propensas ao risco para as perdas. Nessas condições, pode-se dizer que a diferença entre a utilidade de um ganho de $\$ 20$ e um ganho de $\$ 30$ é maior que entre um ganho de $\$ 120$ e um ganho de $\$ 130$. No sentido oposto, a diferença da desutilidade de uma perda de $\$ 30$ e uma perda de $\$ 20$ é considerada como menor que entre uma perda de $\$ 130$ e uma perda de $\$ 120$. Isso acontece mesmo que a diferença absoluta seja a mesma $(\$ 10)$.

O efeito construção aparece quando as pessoas fazem suas escoIhas, mas a título de simplificação do problema enfrentado, acabam por apresentar uma tendência a reformular os dados concernentes. Esse efeito decorre do viés que se produz no momento em que se busca formalizar o problema e quando se processa o tratamento das informações, tendo em vista sua solução. Esse viés encontra-se relacionado à ausência de uma visão global das consequências que as escolhas podem impor. Dessa forma, a formalização do problema exerce uma influência sobre a visão que se tem do mesmo, logo exerce também uma influência na própria escolha, em relação, por exemplo, àquela que alguém faria se dominasse a informação.

A teoria de Kahneman e Tversky (1979) se baseia na decomposição de um processo de decisão em duas etapas: formatação e avaliação. Na primeira fase, os dados objetivos de um problema são percebidos e reformulados; enquanto que na segunda as avaliações das satisfações retidas nos ganhos e perdas são quantificadas e as probabilidades são ponderadas. Uma avaliação de cada perspectiva leva em consideração o valor de cada consequência $v\left(x_{i}\right)$ é ponderada pelo peso da decisão $\pi\left(p_{i}\right)$. São três as propriedades da função $\pi\left(p_{i}\right)$ (EBER; WILLIGER, 2005):

no ponto do status quo, fato esse que gera dificuldades à hipótese da continuidade da função de utilidade marginal. Por outro lado, o ponto de status quo tomado como referência inibe as possíveis mudanças de hábitos e atitudes das pessoas, quando se sabe que a história passada é muito importante na formação das preferências. Por exemplo, a impossibilidade de viajar em férias é muito mais sentida por uma pessoa que já tem um hábito de viajar nas férias que por alguém passou a dispor de tempo e dinheiro para pensar em uma primeira viagem de férias. (GOLLIER; HILTON; RAUFASTE, 2003) 
1. Em condições de certeza, ${ }^{12}$ as pessoas não deformam as probabilidades, de maneira que $\pi(p)>p$ e $\pi(1)=1$. Apesar de se apresentar como monótona em $\mathrm{p}, \pi($. $)$ não pode ser assimilada a uma verdadeira probabilidade, já que essa função não tem boas propriedades nos limites (bordas). ${ }^{13}$

2. Para probabilidades pequenas $\pi(p)>p$, noentanto $\pi(p)+\pi(1-p) \leq 1$ . Isso significa dizer que as pequenas probabilidades são sobreponderadas e as altas probabilidades são subponderadas. Além disso, as sobreponderações são mais pronunciadas que as subponderações.

3. Para uma taxa de probabilidade $q$, a taxa de ponderações é mais próxima da unidade quando as probabilidades são mais baixas que quando elas são mais elevadas. Assim, $\pi(p r) / \pi(p)<\pi(p r q) / \pi(p q)$ para todo $0<p, q, r \leq 1$ Isso leva a crer que $\pi(0,1) / \pi(0,2)>\pi(0,4) / \pi(0,8)$

4. A função л tem o seguinte formato (KAHNEMAN; TVERSKY, 1979):

Gráfico 3 - Exemplo de função л

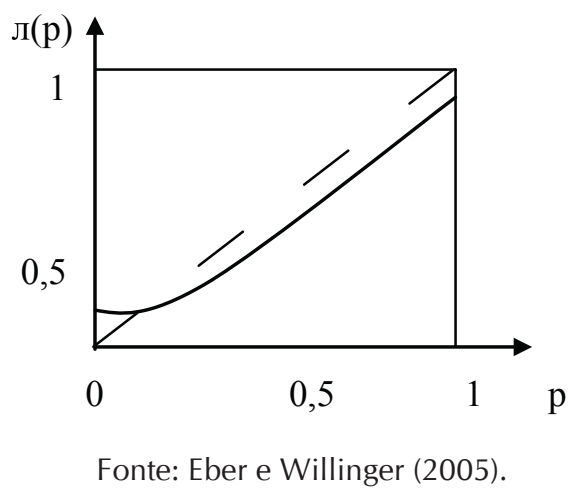

O resultado final em termos de perspectiva do valor da utilidade pode então ser expresso por $P_{V U}=\sum \pi\left(p_{i}\right) v\left(x_{i}\right)$, de maneira que se pode escolher a perspectiva de valor máximo, levando em consideração que as propriedades das funções $\pi e v$ são deduzidas dos efeitos apresentados.

\footnotetext{
${ }^{12}$ Muitas experiências apontam que as pessoas têm uma tendência natural a assimilar a certeza a valores próximos de 0 ou 1. Em sentido oposto, o ditado popular não existe risco zero aparece como expressão da incerteza. (MOUREAU; RIVAUD-DANSET, 2004)

${ }^{13}$ Essa característica faz com que a teoria das perspectivas deixe de ser compatível com as ordens estocásticas, em particular com a de primeira ordem. (PRADIER, 2006) A dominância estocástica de primeira ordem estima que os agentes prefiram os retornos mais elevados em lugar dos menos elevados; a dominância de segunda ordem requer, além da condição de primeira ordem, que os agentes tenham aversão ao risco; enquanto que a dominância de terceira ordem, além do exigido na segunda ordem, especifica que os agentes têm aversão ao risco de maneira crescente.
} 
A função de valor corresponde ao apresentado pelo efeito espelho. Enquanto que a função de ponderação constitui a originalidade do modelo. Isso porque os pesos das decisões não são probabilidades, já que não obedecem a seus axiomas, logo não devem ser interpretados como uma medida do grau de crença. Mas, existe uma interação entre preferência e probabilidade. Kahneman e Tversky (1979) tentam então captar o impacto do aleatório sobre a atração de uma consequência e, de maneira inversa, o impacto de uma consequência sobre a probabilidade; de maneira que as probabilidades podem perfeitamente se apresentar de maneira sobreponderadas ou subponderadas.

Esse é um comportamento muito diferente das situações em que as probabilidades, quando mal conhecidas, em verdade elas podem ser sobre-estimadas ou subestimadas. Por essa razão, as probabilidades passaram a serem consideradas como não proporcionais, ou seja, quanto mais elas são pequenas menos suas variações são percebidas de maneira correta pelas pessoas. Por outro lado, podem-se identificar comportamentos de subcerteza, em que a soma dos pesos das decisões associadas aos acontecimentos é considerada como menor ou maior que a unidade. Dessa forma, na vizinhança de valores extremos, os comportamentos se tornam imprevisíveis e se perde a definição de uma função de utilidade esperada.

Para fechar o raciocínio inovador de Kahneman e Tversky (1979), pode-se dizer que a teoria das perspectivas se distingue da teoria da utilidade esperada von Neumann e Morgenstern em dois aspectos essenciais. Em primeiro lugar, tem-se que a teoria das perspectivas, diferentemente da teoria da utilidade esperada, parte de um julgamento realizado pelos agentes e não dos dados do problema em si. Esses dados podem ser reformulados a partir de novos conhecimentos e informações. Em segundo lugar, a avaliação por parte dos agentes não necessariamente objetivam os estados finais, os quais devem ser maximizados ou minimizados conforme o problema, mas sobre as mudanças em termos de riqueza, bem-estar ou redução das perdas, que ocorrem a partir de uma posição inicial definida por alguma convenção. Mudanças relativas às convenções mudam necessariamente a posição inicial, induzindo a formação de comportamentos diferenciados. (GOLLIER; HILTON; RAUFASTE, 2003)

\section{A Probabilidade Não Aditiva}

As experiências sobre a função utilidade normalmente detectam fortes transgressões ao axioma da independência, a qual assume que a ordem de 
preferência das pessoas não se modifica a partir de transformações lineares. Assim, a ordem de preferência entre duas loterias não deveria se alterar quando essas loterias são combinadas linearmente com uma terceira, mas se altera. Essa alteração é explicada pela modificação na percepção do risco, depois que as loterias iniciais são combinadas com uma terceira. Isso acontece pelo fato de que as novas escolhas passam a respeitar a comonotonia,${ }^{14}$ enfraquecendo o axioma da independência e fazendo com que apareçam incoerências nos processos de escolha. (GAYANT, 1998)

Uma ilustração da comonotonia pode ser dada com o seguinte exemplo (EECKHOUDT, 2001), em que p representa a probabilidade de realização das distribuições x e z, enquanto y representa o somatório de x e z. As esperanças dessas distribuições foram estimadas em $E(x)=1, E(z)=0$ e $E(y)=1$, cujas variâncias são respectivamente $(25,6),(2,8)$ e $(43,3)$.

Quadro 20 - Probabilidades não aditivas

\begin{tabular}{|c|c|c|c|c|c|c|}
\hline $\mathbf{p}$ & $\mathbf{x}$ & $\mathbf{z}$ & $\mathbf{y}$ & $\mathbf{p x}$ & $\mathbf{p z}$ & $\mathbf{p y}$ \\
\hline 0,2 & -20 & -6 & -26 & $-4,0$ & $-1,2$ & $-5,2$ \\
\hline 0,4 & -10 & -4 & -14 & $-4,0$ & $-1,6$ & $-5,6$ \\
\hline 0,3 & 20 & 3 & 23 & 6,0 & 0,9 & 6,9 \\
\hline 0,1 & 30 & 19 & 49 & 3,0 & 1,9 & 4,9 \\
\hline $\mathbf{E}()$. & & & & $\mathbf{1 , 0}$ & $\mathbf{0 , 0}$ & $\mathbf{1 , 0}$ \\
\hline Variância & & & & $\mathbf{2 5 , 6}$ & $\mathbf{2 , 8}$ & $\mathbf{4 3 , 3}$ \\
\hline
\end{tabular}

Fonte: Eeckhoudt (2001).

Desde que $E(z)=0$, a condição de comonotonia é dada por $\left(X_{i}-X_{j}\right)\left(Z_{i}-z_{j}\right) \geq 0 ; \forall i, j$. Uma inspeção do quadro acima permite dızer que ısso e verdade para as variáveis x e z. Assim, quando as coisas vão bem para x o mesmo acontece para $z$ e vice-versa; de maneira que as distribuições x e z são comonotônicas. A partir dessa condição, pode-se dizer que a adição das distribuições x e $z$ permite alcançar uma terceira distribuição (y), imprimindo uma característica interessante, qual seja, y se mostra mais arriscada que $x$, mesmo sabendo que as esperanças estatísticas das duas são iguais. Isso ocorre porque a adição das duas variáveis acaba por impor uma elevação na variância de y comparativamente à de $x$. Dessa forma, os melhores resultados em $x$ tornam-se ainda melhores em $y$, enquanto que os piores resultados em $x$ tornam-se ainda piores em $y$.

\footnotetext{
${ }^{14}$ Por comonotonia entende-se a noção matemática, muito utilizada em coberturas de risco, em que o agente escolhe, para compor seu portfólio, títulos que têm fortes possibilidades de apresentar variações contrárias de seus valores, buscando com isso alcançar uma maior segurança quanto às flutuações nos valores desses títulos. Um exemplo clássico aparece com o preço do petróleo e o preço dos automóveis, de maneira que os respectivos títulos devem flutuar de maneira inversa, que a economia se encontre em expansão ou em recessão.
} 
Um resultado significativo da teoria da utilidade esperada é dado pela concavidade da função de utilidade, decorrendo automática e simultaneamente desse fato que:

1. Uma pessoa avessa ao risco sempre prefere $\mathrm{E}(\mathrm{x})$ em lugar da própria loteria de $\mathrm{x}$.

2. Uma pessoa avessa ao risco prefere $x$ ao invés de y $\operatorname{se} E(\tilde{x})=E(\tilde{y})$, mas se $\mathrm{x}$ for menos arriscado que $\mathrm{y}$.

Essas duas condições não necessariamente são simultaneamente verdadeiras. Dessa forma, pode-se perfeitamente encontrar pessoas que, ao comparar x com a $\mathrm{E}(\mathrm{x})$, se deixam seduzir por uma preferência sistemática em favor da certeza garantida por $\mathrm{E}(\mathrm{x})$, o mesmo sendo válido para y e $\mathrm{E}(\mathrm{y})$. Uma comparação entre as duas distribuições pode levar a que essa pessoa escolha $\mathrm{E}(\tilde{\mathrm{y}})$ em lugar de $\mathrm{E}(\tilde{\mathrm{x}})$, mas é bom salientar que dentre as duas distribuições, mesmo possuindo esperanças iguais, uma (y) se mostra mais arriscada que outra (x). (EECKHOUDT, 2001) O estudo dessa problemática levou ao conceito de probabilidades não aditivas. Os modelos com probabilidades não aditivas tentam captar a ideia de que as probabilidades objetivas não são necessariamente percebidas como tal pelas pessoas, de maneira que elas processam com naturalidade verdadeiras transformações nesse caráter objetivo das probabilidades.

\section{I Utilidade Esperada Dependente da Ordem}

Dentre os modelos que tratam as probabilidades como não aditivas, destaca-se o Rank Dependet Expected Utility (RDEU). Esse modelo propõe uma especificação em que tanto as utilidades dos ganhos quanto as respectivas probabilidades são não lineares. Pode-se afirmar que uma loteria (L) é uma distribuição de probabilidades $\left(p_{1}, p_{2}, p_{3}, \ldots, p_{n}\right)$ sobre resultados $\left(X_{1}, X_{2}, X_{3}, \ldots, X_{n}\right)$, os quais podem ser ordenados de maneira crescente $\left(x_{1}<x_{2}<x_{3}<\ldots<x_{n}\right)$ e representados em valores finitos e numéricos. (GAYANT, 1998)

Em conformidade com os axiomas da utilidade esperada, todo agente econômico possui uma função u de resultados, função essa que se apresenta de forma contínua e estritamente crescente, assumindo o seguinte formato:

$$
U E(L)=\sum_{i=1}^{n} p_{i} u\left(x_{i}\right)
$$


A função u não necessariamente é linear, ao mesmo tempo não há nenhuma razão para considerá-la de maneira diferente da função de resultados de um ambiente de certeza. No entanto, se x é distribuído não linearmente é possível encontrar sobrepesos das probabilidades, de maneira que:

$$
x(p)+x(1-p)>1
$$

Nessas condições, se $x_{1}$ e $x_{2}$ são escolhidos quando $x_{1}$ é levemente preferido à $x_{2}$, tem-se que a utilidade de $x_{1}$ é menor que a soma das utilidades de $\mathrm{x}_{1} \mathrm{e}_{2}$, ponderadas pelos pesos das probabilidades $(\mathrm{w})$, tal como segue:

$$
U\left(x_{1}\right)<w(p) u\left(x_{1}\right)+w(1-p) u\left(x_{2}\right)
$$

Isso deve acontecer mesmo que a perspectiva de $x_{1}$ seja fortemente dominante, de sorte que o resultado será preferido (no mínimo indiferente) com probabilidade igual a unidade..$^{15}$ Kahneman e Tversky (1979) evitam essa implicação ao assumir que as perspectivas dominantes são editadas externamente ao sistema, mas isso leva a um resultado indesejável em que as escolhas ficam intransitivas. (QUIGGIN, 1982)

Surge então a necessidade de se construir uma função similar, mas que leve em consideração a não linearidade das probabilidades. (QUIGGIN, 1982) Isso porque os agentes costumam deformar as probabilidades antes mesmo que as utilidades esperadas sejam calculadas, deformação essa que depende das próprias probabilidades, mas também da forma como as consequências foram ordenadas. Essas transformações das probabilidades podem ser captadas por uma variável $\varphi$ definida no intervalo $[0,1]$, estritamente crescente e que $(0)=0$ e $(1)=1$, de maneira que $\sum_{i}\left(p_{i}\right)=1$. Essa nova funçao, denominada de utilidade antecipada (UA), pode tomar a seguinte forma:

$$
U A(L)=\sum_{i=1}^{n} \varphi_{i}\left(p_{i}\right) u\left(x_{i}\right)
$$

Com isso se busca retratar o comportamento das pessoas de maneira mais realística, na medida em que acontecimentos de baixa probabilidade são ponderados por percentuais mais elevados que suas respectivas probabilidades objetivas, enquanto que os acontecimentos de alta probabilidade são ponderados por percentuais menos elevados. Essas ponderações deformadas sugerem que a função de transformação das probabilidades tenha um formato de um S invertido, diferentemente de uma função de

\footnotetext{
${ }^{15}$ É interessante lembrar que se $\mathrm{w}$ for linear, tem-se a possibilidade de retornar ao modelo de von Neumann e Morgenstern, dado que $w(p)+w(1-p)=w(1)$ (QUIGGIN, 1982)
} 
transformação simples que se apresenta de forma côncava, tal como mostram os gráficos a seguir.

Gráfico 4 - Probabilidade Deformada e Função de Transformação Côncava

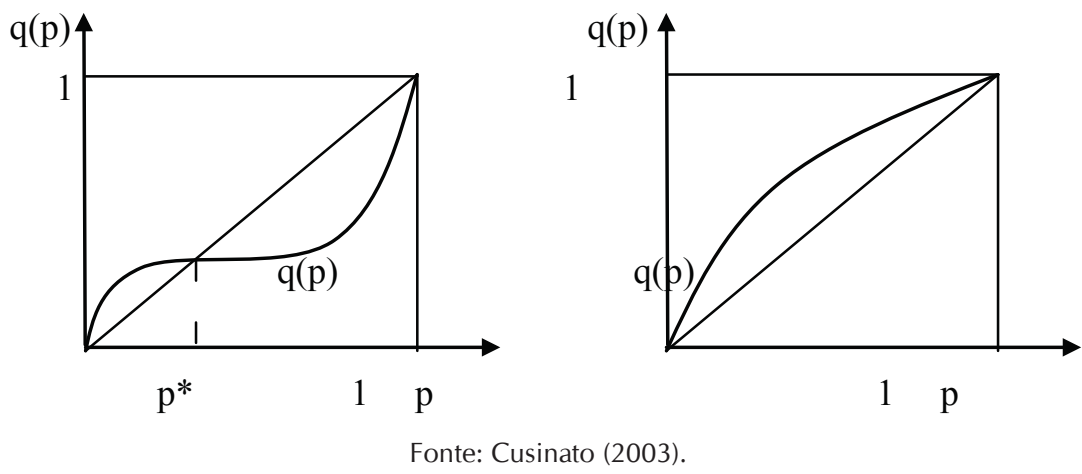

O primeiro gráfico representa as probabilidades deformadas, se sorte que $q(p)=p$ apenas no ponto em que $p=p$. Para $p<p$ tem-se um segmento côncavo da curva e aponta um sobrepeso das probabilidades e quanto $p>p$ tem-se um segmento convexo da curva, apontando uma subponderação das probabilidades. O segundo gráfico apresenta uma função de transformação côncava, em que os piores resultados recebem pesos mais elevados que os melhores resultados, caracterizando as condições normais de aversão ao risco.

A consideração conjunta de utilidades e probabilidades não lineares pode conduzir a uma associação de um valor numérico mais elevado a uma loteria $L^{\prime}$ que a uma loteria $L$, mesmo quando $L$ domina $L^{\prime}$ em termos estocásticos de primeira ordem, ou seja, no sentido de que o resultado alcançado pela escolha de $L$ é tão bom quanto o resultado obtido pela escolha de L'. (GAYANT, 1998) O modelo RDEU aparece como grande auxiliar para afastar esse tipo de dificuldade.

Nessas condições, o modelo RDEU pode ser construído a partir de dois princípios:

1. Quem decide, considera a variação da utilidade e não seu valor absoluto, fato esse que requer uma classificação da utilidade das consequências, de maneira que as preferências influenciam a percepção das probabilidades ; 
2. Quem decide, utiliza as probabilidades acumuladas em lugar das simples. Esses dois princípios permitem considerar a deformação das probabilidades observadas quando dos testes experimentais. ${ }^{16}$ A não aditividade das probabilidades imprime uma idéia de que em realidade as pessoas tratam as probabilidades como não lineares em seu dia a dia, de maneira que podem perfeitamente subponderá-las, sem nenhum compromisso com a teoria da utildade esperada, em que a soma das probabilidades fecha com a unidade.

Para uma apresentação da lógica desse modelo (MOUREAU; RIVAUD-DANSET, 2004) em um primeiro momento vão-se supor três estados

da natureza, aos quais estão associadas às probabilidades $\left(\pi_{1}, \pi_{2}, \pi_{3}\right)$. Considere-se então a função de transformação definida de $[0,1]$ em $[0,1]$. A função de preferências é representada por $V(X)$, de maneira que:

$$
\text { 1. } V(X)=u\left(x_{1}\right)+\left(\pi_{2}+\pi_{3}\right)\left[u\left(x_{2}\right)-u\left(x_{1}\right)\right]+\left(\pi_{3}\right)\left[u\left(x_{3}\right)-u\left(x_{2}\right)\right] .
$$

A interpretação dessa função permite informar que a pessoa que decide raciocina em termos de variação das utilidades. Assim, ela começa avaliando a utilidade mínima para receber $u\left(x_{1}\right)$; em seguida ela introduz um aumento possível em sua utilidade, tomando o diferencial das utilidades $\left[u\left(x_{2}\right)-u\left(X_{1}\right)\right]$ e ponderando por uma probabilidade transformada de $\left(\pi_{2}+\pi_{3}\right)$; por fim, ela associa a última variação de sua utilidade ponderada pela probabilidade transformada de $\left(\pi_{3}\right)$. Os pesos de uma decisão, que deformam as probabilidades acumuladas, se modificam segundo a ordem das consequências.

2. $V(X)=u\left(x_{1}\right)+\left[\left(\pi_{1}+\pi_{2}+\pi_{3}\right)-\left(\pi_{2}+\pi_{3}\right)\right]+u\left(x_{2}\right)\left[\left(\pi_{2}+\pi_{3}\right)-\left(\pi_{3}\right)\right]-u\left(X_{3}\right)\left(\pi_{3}\right)$

Esse modelo engloba a utilidade esperada de von Neumann e Morgenstern. Para uma demonstração basta transformar a expressão (1) até chegar à expressão (2). Nessa última $\varphi$ não apresenta a propriedade aditiva, mas, ao se supor que as probabilidades são transformadas linearmente, então os pesos das decisões podem ser adicionados à expressão (2), permitindo que ela seja reescrita como segue:

$$
\text { 3. } V(X)=u\left(X_{1}\right)\left(\pi_{1}\right)+u\left(x_{2}\right)\left(\pi_{2}\right)+u\left(X_{3}\right)\left(\pi_{3}\right)
$$

\footnotetext{
${ }^{16}$ Segundo Kahneman e Tversky (1979), a função que opera essa transformação das probabilidades acaba por subponderá-las, de maneira que $V(X)<E U(X)$. (MOUREAU; RIVAUD-DANSET, 2004)
} 
Como $\left(\pi_{1}\right)=\pi_{1} ; \quad\left(\pi_{2}\right)=\pi_{2}$ e $\left(\pi_{3}\right)=\pi_{3}$, pode-se perfeitamente retornar à função da utilidade esperada original, permitindo afirmar que o modelo de von Neumann e Morgenstern é um caso particular do modelo RDEU.

Para o modelo RDEU, uma pessoa que possua uma utilidade marginal crescente pode perfeitamente se comportar de maneira avessa ao risco. Essa constatação permite afirmar que o índice absoluto de aversão ao risco de Pratt deixa de ser uma medida de aversão ao risco e passa a ser explicado como uma medida da sensibilidade da utilidade marginal. Essa interpretação abre novas noções quanto à aversão ao risco: a) aversão ao crescimento do risco; b) aversão ao crescimento monótono do risco e c) aversão à incerteza ou aversão à ambigüidade, que somente aparece quando as probabilidades são não aditivas. Esse conceito de aversão permite uma solução satisfatória ao paradoxo de Ellsberg ao concretizar uma intuição de que os agentes econômicos preferem enfrentar uma situação de incerteza probabilística ao invés de uma situação em que as probabilidades dos acontecimentos não são conhecidas ou apenas parcialmente conhecidas. (GAYANT, 1998) ${ }^{17}$

Uma ilustração desse modelo é dada pelo seguinte exemplo. (MOUREAU; RIVAUD-DANSET, 2004) Um condutor deve escolher entre dois trajetos A ou B, sabendo que o tempo do percurso encontra-se condicionado ao estado aleatório de densidade do tráfico. Ele dispõe das probabilidades de três estados da natureza (trafégo engarrafado, carregado e fluído), sobre as quais esse condutor opera deformações de maneira a perder o caráter da aditividade das probabilidades. Os dados para o trájeto A são apresentados nas duas primeiras linhas no quadro a seguir.

\footnotetext{
17 Essa conclusão tem uma implicação direta na teoria dos jogos. A presença de probabilidades não aditivas permite, por exemplo, questionar a existência de equilíbrio de Nash com estratégias mistas, na medida em que essas probabilidades perdem seu caráter de soma unitária. O equilíbrio de Nash fica restaurado apenas nos casos em que os jogadores respeitam o axioma da independência. A consequência desse argumento é muito forte, já que ele implica em poder afirmar que normalmente os jogadores escolhem estratégias puras, deixando de recorrer às estratégias aleatórias. Isso permite o aparecimento de ações cooperativas no dilema do prisioneiro com repetições finitas, ao tempo em que estabelece comportamentos prudentes. (GAYANT, 1998)
} 
Quadro 21 - Probabilidades por Estados da Circulação

\begin{tabular}{|c|c|c|c|}
\hline \multirow{2}{*}{ Informações } & \multicolumn{3}{|c|}{ Estados da Circulação } \\
\hline & Engarrafado & Carregado & Fluído \\
\hline $\mathrm{U}(\mathrm{x})$ & 15 & 70 & 100 \\
\hline Probabilidade (ఐi) & 0,7 & 0,2 & 0,1 \\
\hline$U(x i)-U(x i-1)$ & 15 & 55 & 30 \\
\hline Probabilidades acumuladas & 1 & 0,3 & 0,1 \\
\hline $\begin{array}{l}\text { Probabilidades acumuladas } \\
\text { transformadas }\end{array}$ & 1 & $\varphi(0,3)$ & $\varphi(0,1)$ \\
\hline Utilidade (RDEU) & 15 & $\varphi(0,3) 55$ & $\varphi(0,1) 30$ \\
\hline
\end{tabular}

Após uma ordenação crescente das utilidades, uma interpretação desse quadro consiste em dizer que o condutor inicialmente avalia a menor utilidade que ele está convencido de alcançar. Essa utilidade corresponde ao tráfego engarrafado. Em seguida, ele considera os diferenciais de utilidade entre os tráfegos carregado e engarrafado e entre o fluído e o carregdo. Ness instante, as probabilidades são transformadas pela agregação que parte do tráfego fluído ao engarrafado. Calculando o valor dos diferenciais de utilidade, ponderados pelas probabilidades transformadas chega-se ao valor esperado em condições de utilidade esperada dependente do ordenamento. Esse valor é estimado em: $15(0,1+0,2+0,7)+55(0,2+0,1)+30(0,1)=34,5$

. Com as utilidades e probabildades do trajeto $B$, procede-se ao mesmo tipo de estimativa, para então poder comparar os dois resultados, aquele que apresentar o maior valor da utilidade esperada dependente do ordenamento deverá ser o trajeto escolhido pelo condutor.

\subsection{Utilidade Esperada a La Choquet}

O modelo Choquet Expected Utility (CEU) guarda uma analogia muito forte com o modelo RDEU, na medida em que as probabilidades são também consideradas como não aditivas. Mas, enquanto no modelo RDEU as probabilidades são conhecidas, muito embora sofram deformações, o modelo CEU essas probabilidades são desconhecidas, tal como no paradoxo de Ellsberg. ${ }^{18}$ Procurando responder a esse paradoxo, o modelo da utilidade esperada à la Choquet introduz a ideia de que as decisões devem

\footnotetext{
${ }^{18} \mathrm{O}$ paradoxo de Ellsberg apontou que o raciocínio é diferenciado, caso as probabilidades dos eventos sejam ou não conhecidas.
} 
ser tomadas a partir das crenças, ou seja, pelo grau de credibilidade que se possa atribuir a uma evidência.

Para alcançar a medida das crenças deve-se recorrer ao conceito de capacidade. Entende-se por capacidade uma função $w($.$) , cujas pro-$ priedades são menos restritivas em relação às funções de probabilidade. A capacidade de Choquet permite a mensuração de observações pouco exatas do tipo "tenho pelo menos $70 \%$ de chance de ser aprovado no exame final de matemática", de maneira que a verdadeira probabilidade é desconhecida. Dessa forma, na ausência de informações quanto à probabilidade de ocorrência do fenômeno, a capacidade de decisão pode ser iniciada levando-se em consideração o pior estado da natureza, ou seja, exercendo um papel pessimista, a pior possibilidade pode ser $40 \%$ de chance de obter êxito no exame de matemática.

Calculando a utilidade para essa probabilidade inicial, deve-se proceder a uma suplementação de utilidades hipotéticas, as quais são ponderadas pela função $w($.) que de maneira subjetiva oferece as possibilidades de ocorrência de melhoria no desfecho final do fenômeno. Assim, o estudante de matemática, cuja informação é imprecisa, deve se comportar em termos de capacidade ou plausibilidade mínima para tomar uma decisão entre continuar estudando para enfrentar o exame ou desistir.

A imprecisão da informação apresenta várias origens, dentre as quais se destacam a ambiguidade da informação (imperfeição da informação) e a complexidade da situação. Nessas circunstâncias, as decisões são tomadas a partir de uma análise global do problema, em que se parte de uma constatação mínima inicial e vão-se implementando novas possibilidades à medida que se avança na obtenção de novas informações.

\section{Conclusão}

Existe hoje certo consenso entre os economistas que os modelos tipo RDEU explicitam algumas lacunas deixadas pela teoria da utilidade esperada. Isso não significa uma ruptura em relação ao modelo da utilidade esperada. É perfeitamente aceitável que os modelos tipo RDEU acabam por generalizar os resultados obtidos pelos modelos da utilidade esperada, da mesma forma que esses últimos constituíram a generalização dos modelos da esperança de ganhos. Os modelos RDEU ganham, portanto, espaço analítico, principalmente quando de trata de fenômenos raros, cujas probabilidades são muito pequenas dadas suas possibilidades analíticas e 
prospectivas. As oportunidades de uso empírico dessas modelações estão, pois, na ordem do dia para estudos e decisões que encerram incerteza e risco.

\section{Referências}

CUSINATO, Rafael T. Teoria da decisão sob incerteza e a hipótese da utilidade esperada: conceitos analíticos e paradoxos. 181 f. 2003 Dissertação (Mestrado em Economia) - Faculdade de Ciências Econômicas, Universidade Federal do Rio Grande do Sul, 2003. Disponível em: < http://www.lume.ufrgs.br/bitstream/ handle/10183/1961/000362539. pdf? sequence =1 > . Acesso em: 18 jul. 2012.

EBER, N; WILLINGER, M. L'économie expérimentale. Paris : La Découverte, 2005.

EECKHOUDT, Louis. Espérance d'utilité et nouveaux modèles de choix dans le risque: une connivence cachée. Revue d'analyse économique, Paris, v. 77, n. 4, p. 499-516, déc., 2001. Disponivel em : < http://www.erudit.org/revue/ae/2001/v77/n4/602362ar. pdf $>$. Acesso em: 18 jul. 2012.

GAYANT, Jean-Pascal. L'apport des modèles non-additifs en théorie de la décision dans le risque et I'incertain. Revue Française d'Économie, Paris, v. 13, n. 1, p. 199-227, 1998.

GOLLIER, Cristian; HILTON, Denis; RAUFASTE, Eric. Daniel Kahneman et I'analyse de la décision face au risque. Revue d'économie politique, Paris, n. 3, v. 113, p.295-301, 2003. Disponivel em: < http://www.cairn.info/revue-d-economie-politique-2003-3page-295.htm > . Acesso em; 18 jul. 2012.

GUERRIEN, Bernard; NEZEYS, Bertrand. Microéconomie et calcul économique. Paris: Economica, 1987.

JOKUNG-NGUÉNA, Octave. Microéconomie de l'incertain: risques et décision. Paris: Dunod, 2001.

KAHNEMAN, Daniel; TVERSKY, Amos. Prospect theory: an analysis of decision under risk. Econometrica, Chicago, v. 47, n. 2, mar., p. 263-292, 1979. Disponivel em: < http://www.hss.caltech.edu/ camerer/Ec101/ProspectTheory.pdf > . Acesso em : 18 jul. 2012.

KAST, Robert. La théorie de la decision. Paris: La découverte, 1993.

KNIGHT, Frank H. Risk, uncertainty, and profit: hart, Schaffner, and Marx Prize Essays. Boston: Houghton Mifflin, 1921. n. 31.

MOUREAU, Nathalie; RIVAUD-DANSET, Dorothée. L'incertitude dans les théories économiques. Paris: La découverte, 2004.

PRADIER, Pierre-Chales. La notion de risque en économie. Paris: La découverte, 2006.

QUIGGIN, John. A theory of anticipated utility. Journal of economico behavior and organization, Tennessee, v. 3, n. 4, p. 323-343, dez., 1982. 
TVERSKY, Amos; KAHNEMAN, Daniel. Judgement under uncertainty: heuristics and biases. Science, New York, v. 185, n. 4157, p. 1124-1131, set., 1974. Disponivel em: < http://www.math.mcgill.ca/vetta/CS764.dir/judgement.pdf>. Acesso em: 18 jul. 2012.

VARIAN, Hal. Analyse microéconomique. Paris: De Boeck, 2000.

106 | Nexus Econômicos - CME-UFBA 